Alma Mater Studiorum - Università di Bologna DEPARTMENT OF ECONOMICS

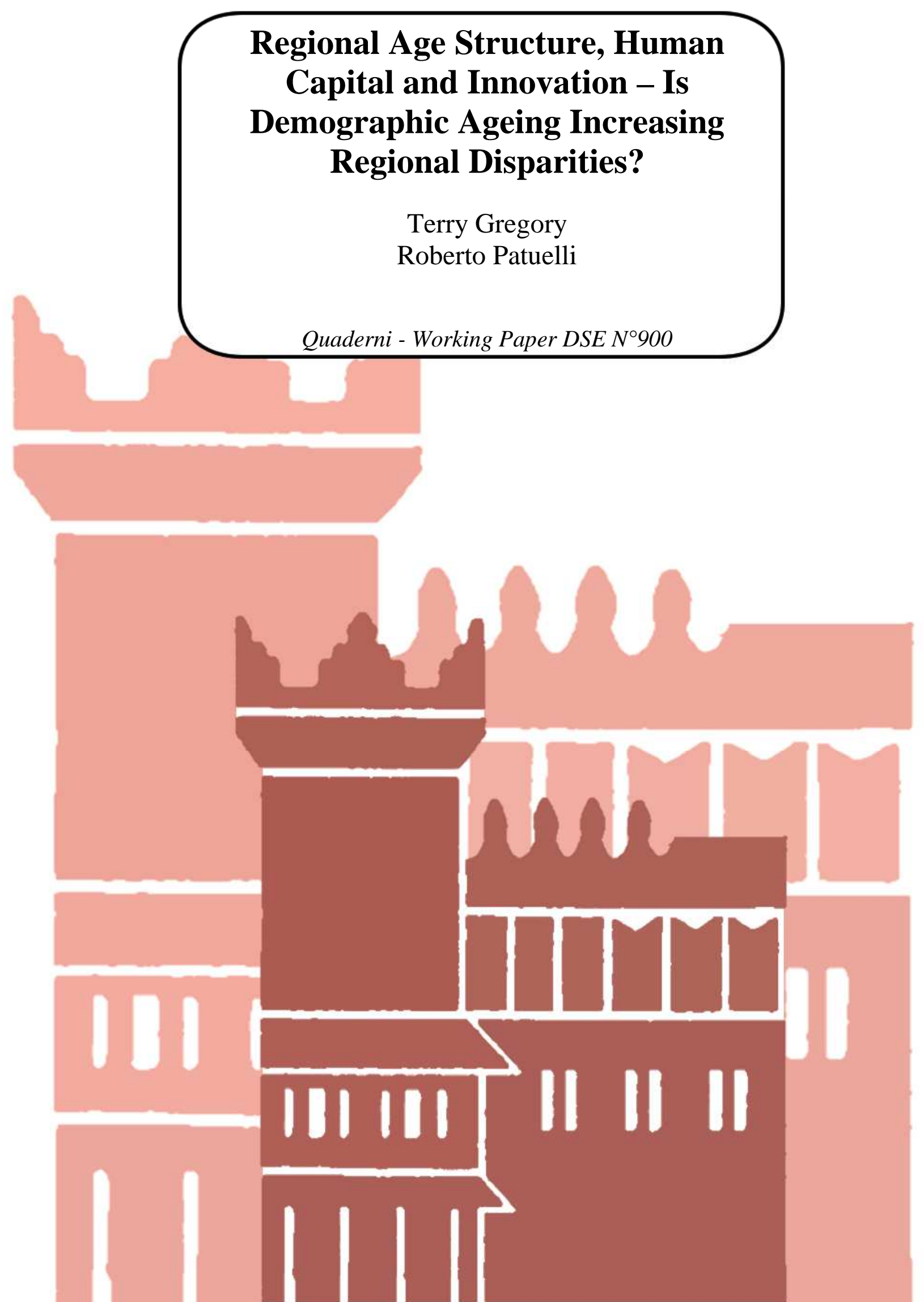




\section{Non-technical summary}

Demographic ageing has increasingly become one of the most pressing challenges that industrialized economies are facing in the 21st century. In particular, this trend has raised the concern that an ageing workforce may reduce productivity, innovative capability and thus, ultimately, competitiveness in the global, knowledge-based economy. More strikingly, demographic ageing is expected to affect regions in very different ways on a regional scale. This might, in turn, lead to increasing regional disparities if innovative regions attract particularly young and educated workers and trigger a cumulative process towards more polarized regions. In addition, such regional disparities might further be enhanced by spatial spillovers induced by formal and informal interactions across firms and regions.

This paper describes the spatial and temporal pattern of regional innovation output, workers age structure and human capital by conducting an Exploratory Space-Time Data Analysis for German regions between 1995-2008. First, we detect spatial regimes or other forms of spatial heterogeneity to help specifying testable hypotheses for the implementation of regression models that aim at assessing the link between regional age structure and innovation. Second, we exploit newly developed visualisation methods that allow investigating the space-time dynamics of the spatial distributions and help detecting a potential reinforcement of clusters and spatial polarization tendencies.

Overall, the results reveal a great divide across German regions. On the one hand, there are highly innovative regions that cluster in urban and rural counties in West and South Germany and mostly coincide with young and heterogenous workers. On the other hand, less idea-driven regions cluster in rural and sparsely populated areas in East Germany and coincide with an old and homogenous working population. For the space-time developments of the different measures, we observe different patterns. For instance, despite small improvements in patent production in East Germany, the spatial distribution of innovation has not changed much during the observed time period. In contrast, the local age structure shows a strong demographic polarization trend: major cities are experiencing declining average ages (relative to the national value), whereas the age distribution of rural areas is shifting upwards. East Germany with a large rural landscape is particularly affected by these trends, thus further increasing the demographic divide between both parts of the country.

The specific dynamic patterns observed suggest that the divide will further increase along agglomeration lines. In particular, major cities are gaining importance for young and educated workers since agglomerated ('thick') labour markets increasingly offer several advantages such as cultural infrastructure and a better matching efficiency between workers and employers. Our investigations show that losing regions thereby have a small probability to reverse the trend due to strong neighbouring forces and clusterwise path dependence. For policy makers of such regions it will therefore become more important to develop strategies to counteract the geographical poverty trap such as 'big push' type of policies. 


\title{
Regional Age Structure, Human Capital and Innovation - Is Demographic Ageing Increasing Regional Disparities?*
}

\author{
Terry Gregory ${ }^{\dagger}$ \\ ZEW Centre for European Economic Research, Mannheim, Germany \\ Roberto Patuelli \\ University of Bologna, Italy \\ The Rimini Centre for Economic Analysis (RCEA), Italy
}

August 2013

\begin{abstract}
Demographic change is expected to affect labour markets in very different ways on a regional scale. The objective of this paper is to explore the spatio-temporal patterns of recent distributional changes in the workers age structure, innovation output and skill composition for German regions by conducting an Exploratory Space-Time Data Analysis (ESTDA). Beside commonly used tools, we apply newly developed approaches which allow investigating the space-time dynamics of the spatial distributions. We include an analysis of the joint distributional dynamics of the patenting variable with the remaining interest variables. Overall, we find strong clustering tendencies for the demographic variables and innovation that constitute a great divide across German regions. The detected clusters partly evolve over time and suggest a demographic polarization trend among regions that may further reinforce the observed innovation divide in the future.
\end{abstract}

Keywords: innovation, workforce age structure, exploratory space-time data analysis, regional disparities

JEL: J11, O31, R11, R12, R23

${ }^{*}$ The authors would like to thank Melanie Arntz, Stephan Dlugosz, Konrad Stahl, Ulrich Zierrahn, participants of the annual conferences of the North American Regional Science Council, European Association of Labour Economists, European Society of Population Economics, European Regional Science Association, Ph.D. Workshop on "Perspectives on (Un-) Employment" and seminar participants at the University of Regensburg and Universitat Jaume I for valuable comments. We further thank the Fritz Thyssen Foundation for financial support. The research for this paper was partly carried out during the first author's stay at the Faculty of Economics-Rimini of the University of Bologna, whose hospitality is gratefully acknowledged.

${ }^{\dagger}$ Terry Gregory (corresponding author), ZEW Centre for European Economic Research, L7, 1 D-68161 Mannheim, Germany, e-mail: gregory@zew.de, phone: +49-621-1235-306, fax: +49- 621-1235-225.

${ }^{\ddagger}$ Roberto Patuelli, Department of Economics, University of Bologna, Rimini Campus, via Angherà, 22, 47921 Rimini (RN), Italy, e-mail: roberto.patuelli@unibo.it, phone: +39-0541434276 fax: +39-02-700419665. 


\section{Introduction}

Demographic ageing has increasingly become one of the most pressing challenges that industrialized economies are facing in the 21st century. According to the latest Eurostat projections over the next 50 years, workforce ageing will continue in all European countries, though the magnitude, speed and timing are likely to vary. This demographic trend has raised the concern that an ageing workforce may reduce productivity, innovative capability and thus, ultimately, competitiveness in the global, knowledge-based economy. More strikingly, workforce ageing is very likely to affect regions in very different ways. In particular, demographic ageing may further increase regional disparities if innovative regions attract particularly young and educated workers, which may in turn trigger a cumulative process towards more polarized regions (Kanbur and Rapoport 2005, Fratesi and Riggi 2007). Such divergence processes due to agglomeration forces and migration have already been discussed for the US labour market by Moretti (2011). For the German labour market such phenomena are less clear due to limited worker and firm mobility relative to the US. In this regard, Puga (2002) provides a discussion, based on location theories, of the possible (negative) causes of polarization within European countries.

In addition, such regional disparities might further be enhanced by spatial spillovers induced by migration movements and social interaction across firms and regions. For instance, workers at highly productive ages may interact with those from other age groups, therefore generating spatial externalities. Also, regional performance measures such as innovation are known to depend on a knowledge transfer between firms and regions that results from sharing ideas and information through informal conversation and interactions (see e.g. Glaeser 1999, Jaffe et al. 1993). Investigating the structure and evolution of such spatial dependence might thus reveal additional insights into spatial polarization tendencies. This could be particularly important for researchers evaluating the impact of demographic ageing processes using regional (areal) data. Spatial dependence or autocorrelation in such data may, if neglected, lead to inconsistent or inefficient estimates in firm- or regional-level analyses (Anselin 1988, Anselin and Florax 1995). ${ }^{1}$.

The objective of this paper is to describe the spatial and temporal pattern of regional innovation output and workers age structure by conducting an Exploratory Space-Time Data Analysis (ESTDA) for innovation and demographic measures. We define regions as counties and distinguish between their degree of urbanisation. The aim is to detect spatial regimes (e.g., systematic

\footnotetext{
${ }^{1}$ Spatial dependence or autocorrelation can be defined as the coincidence of value similarity with locational similarity (Anselin 2001).
} 
differences in data structure due to differing structural characteristics) or other forms of spatial heterogeneity to help specifying testable hypotheses for the implementation of regression models that aim at assessing the link between regional age structure and innovation. For instance, if specific spatial clusters or outliers are detected, econometric techniques which explicitly include the spatial structure of the exploratory variables could be applied.

There are several studies that explore the spatial distributions of economic performance or income across European regions using local and global measures of spatial association (Le Gallo and Ertur 2003, Ertur and Koch 2006, Dall'erba 2005, Patacchini and Rice 2007). However, these studies use more general indicators of economic performance and consider only partly space-time dynamics. Exceptions are the study by Le Gallo (2004) and more recent studies by Hierro et al. (2013) and Fazio and Lavecchia (2013) which deal with the persistence of regional disparities by exploiting spatial transition probabilities. We build on this literature and extend these approaches by newer visualisation methods for a comprehensive Exploratory Space-Time Data Analysis (ESTDA) analysis of the German regional innovation system and demographic measures.

Our contribution is threefold. Firstly, we describe the spatial distributions of regional age structure, human capital and innovation in the interesting case of a strongly ageing Germany and discuss the corresponding link. We thereby not only focus on the average age of workers, but also consider age diversity in order to capture a more complete picture of the age distribution. By including the share of high-skilled workers in our analyses we additionally capture one of the most important drivers of regional innovation. Secondly, we use a rich data set from the European Patent Office (EPO) that includes all published patents in Germany. By focusing on patents as one direct measure of the innovation process at the regional level, we are better able to capture innovativeness than more general indicators of economic performance such as productivity and economic growth. Thirdly, instead of only using static (spatial) methods such as Local Indicators of Spatial Association (LISA), we apply newly developed visualization tools such as directional Moran scatterplots developed by Rey et al. (2012) and spatial drift maps originally proposed by Cressie (1993). These methods allow investigating the space-time dynamics of the spatial distributions and help detecting a potential reinforcement of clusters and spatial polarization tendencies. In addition, we calculate LISA transition probabilities suggested by Rey (2001) to study the persistence of regional disparities. To the authors' knowledge, this paper is the first to combine all the above methods and provide a comprehensive ESTDA on the 
themes of labour force ageing and innovation output.

Overall, the results reveal a great divide across German regions. On the one hand, highly innovative regions cluster in urban and rural counties in West and South Germany and mostly coincide with young and heterogenous workers. On the other hand, less idea-driven regions cluster in rural and sparsely populated areas in East Germany and coincide with an old and homogenous working population. Investigating the space-time dynamics of these clusters, we further show that, despite small improvements in patent production in East Germany, the spatial distribution of innovation has not changed much during the observed time period. In contrast, the age structure shows a strong demographic polarization trend: major cities are experiencing declining average ages (relative to the national value), whereas the age distribution of rural areas is shifting upwards. East Germany with a large rural landscape is particularly negatively affected by these trends, thus further increasing the demographic divide between both parts of the country. Despite these developments, East German regions appear to be transitioning from a highly age-homogeneous workforce towards a more heterogenous one with lower human capital. Our findings further indicate that regions have a low probability to reverse their condition (when poor) due to strong neighbouring forces and clusterwise path dependence. We find evidence of a concentration process for which ideas and dynamic (age-heterogeneous and highly skilled) workers tend to increasingly cluster in few successful regions (cities), while the low-performing areas increase in geographical size.

The paper is structured as follows. Section 2 introduces the database and provides first descriptives of the data. Section 3 presents the ESTDA including tests on global and local spatial associations as well as space-time dynamics. Finally, Section 4 concludes.

\section{Data}

We define the workforce as all fulltime-employed workers in a region, i.e. excluding unemployed individuals. For the calculation of the workforce age structure, we exploit the regional file of the Sample of Integrated Labour Market Biographies (SIAB) from the Institute of Employment Research (IAB) for the years 1995-2008. The data set is an employment subsample provided by the German Federal Employment Agency and contains information on workers that are subject to social insurance contributions by their employers, thus excluding civil servants and self-employed individuals. The data includes individual employment histories on a daily basis 
and contains, among others, information on the age and skills of workers. We use annual cross sections at the the cut-off date 30th June and calculate regional indicators of the demographic composition including the average age, age dispersion (standard deviation) and the share of high-skilled workers. ${ }^{2}$ We restrict the analysis to employed individuals subject to the social insurance contribution, that is, excluding minor and unemployed workers. Furthermore, we restrict our data set to working individuals between 18 and 65 years of age to avoid any selection problems that would be given, for instance, by the fact that those few employed workers below 18 constitute a certain, particularly low-educated group. The data are calculated based on 332 regions ${ }^{3}$. Correspondingly, we define regions as counties and distinguish between their degree of urbanisation.

As a measure of regional innovativeness, we use patent data which are provided by the European Patent Office (EPO). The use of such direct outcome measures is still rare in the literature dealing with the effects of ageing workers on competitiveness, especially in regional level studies ${ }^{4}$, but should be better able to capture innovativeness than more general indicators of economic performance. Our data set contains patent data both at the applicant and inventor level. Whereas the applicant is the holder of the patent right, the inventors are the actual inventors cited in the document. We focus on patent inventors since we are interested in the spatial distribution of the actual inventors rather than the location of the formal holder of the patent, which is often one of the firm's headquarters. Since patents may have been developed by serval inventors located in different regions, we apply a fractional counting approach to assign to every region the respective share of the patent. For instance, an inventor who developed a patent in Mannheim with one further individual working abroad would generate 0.5 patents for this region. Following this procedure for each of the 332 regions, we calculate the number of patent applications for the years 1995-2008. Since the number of inventions of a region may simply reflect its size rather than the knowledge production efficiency, we furthermore condition the number of patents (multiplied by 100) by the number of employed workers of the region to obtain a measure of patent production per 100 workers.

There are several advantages and disadvantages of using patenting data on the regional level (Giese and von Reinhard Stoutz 1998, Giese 2002). On the one hand, patent applications are a

\footnotetext{
${ }^{2}$ To encounter missings in the education variable, we apply the imputation procedure suggested by Fitzenberger et al. (2006).

${ }^{3}$ We aggregated Aachen Kreis and Aachen Stadt to Aachen Städteregion, thus reducing the original number of SIAB regions from 333 to 332.

${ }^{4}$ See, for instance, Brunow and Hirte (2006), Feyrer (2008) and Lindh and Malmberg (1999).
} 
useful indicator of research and invention activities on the local level, as they include information on the regional origin of inventor activities, i.e. place of residence and therefore indirectly the location of the research institute. On the other hand, not every invention becomes the subject of a patent application, nor does a patent necessarily become a marketable product or process. Moreover, the reasons for a patent application may not only rest on protecting an invention against unjustified use, but may reflect strategic concerns such as securing and extending regional markets, prestige advertisement and the demonstration of innovative capacity to the economic counterparts. Despite these disadvantages, empirical evidence by Acs et al. (2002), who provide an exploratory and a regression-based comparison of the innovation count data and data on patent counts at the lowest possible levels of geographical aggregation, suggests that patents provide a fairly reliable measure of innovative activity. Also, the survey study by Griliches (1998) concludes that patents are a good indicator of differences in inventive activity across different firms.

Table 1 shows descriptive statistics for patents per 100 worker, average age, age dispersion and the share of high-skilled workers for the 332 regions during the 14-year period by East and West Germany. In total we have $332 \times 14=4648$ observations for each variable. According to the summary statistics, West (East) German regions generate, on average, 5.7 (1.21) patents per 100 workers. The variation across regions and time is large. For instance, the most innovative region produced 35.24 patents per 100 worker, whereas other regions did not exhibit any patents at all during the 14 year period. The variation in the share of high-skilled workers is similarly large. In contrast, workers in East Germany are, on average, 41.2 years old, that is 1.1 years older than their West German counterparts. However, the regional variation within both parts of the country and across time is still substantial. Whereas young regions exhibit a mean age of 36.4, the region with the oldest workforce comprises workers with, on average, 43.9 years of age.

In order to better grasp the spatial distributions, Figure 1 plots the regional quantile maps of the average values over the 14-year time period. For instance, the first quintile (light blue) depicts the values for the 20 per cent least innovative regions whose values range from 0.2 to 1.4 patents per 100 workers. The fifth quintile contains the values for the most innovative regions (dark blue), with values ranging from 7.6 to 29 . The maps show that innovations are mostly generated in urbanized counties around West German cities Wolfsburg, Cologne, Darmstadt, Stuttgart, Freiburg, Nueremberg and Munich. In contrast, only a few East German cities such 
Table 1: Descriptive statistics for 332 German regions, by East and West (1995-2008)

\begin{tabular}{lrrrr}
\hline Variable & Mean & Sd & Min & Max \\
\hline East Germany (n=910) & & & & \\
Patents per 100 worker & 1.21 & 1.36 & 0.00 & 11.07 \\
Average age & 41.19 & 0.96 & 38.82 & 43.43 \\
Age dispersion & 10.15 & 0.28 & 9.37 & 11.42 \\
Share of high-skilled (in \%) & 7.06 & 2.96 & 2.56 & 18.23 \\
\hline West Germany (n=3738) & & & & \\
Patents per 100 worker & 5.71 & 4.66 & 0.00 & 35.24 \\
Average age & 40.08 & 1.08 & 36.40 & 43.98 \\
Age dispersion & 10.39 & 0.37 & 9.13 & 11.75 \\
Share of high-skilled (in \%) & 5.13 & 3.24 & 0.20 & 21.53 \\
\hline
\end{tabular}

as Jena seem halfway competitive in the production of knowledge.

The map for the average age and age dispersion further reveals that almost all East German regions have on old and homogenous workforce indicating that plant closures and out-migration of young workers after reunification has strongly affected the age structure of the East German labour force. ${ }^{5}$ Only Dresden shows a high age diversity which might reflect improving job perspectives for young and qualified workers that are complementing the large stock of old workers in this region. In contrast, only a few West German regions comprise a high average workforce age including regions around Kiel, Bremershaven, Hannover, Kassel, Dortmund, Mannheim and Pforzheim. Interestingly, regions that have an old workforce in West Germany are not typically rural regions (compare Table 7 in the appendix). In fact, the workforce is younger and more heterogenous, on average, in rural compared to urban areas. However, it remains to be explored how workforce ageing has developed over time during the observed time period in order to derive conclusions for potential polarization trends.

The map for the share of high-skilled workers clearly indicates that skilled labour is located in agglomerated areas. This is particularly true for East Germany. Overall, the maps demonstrate that regions in East Germany exhibit higher shares of high-skilled workers compared to West Germany. However, the level differences between both parts of the country might be explained through the fact that, after reunification, the share of individuals with a college or university degree was twice as high in Eastern compared to Western Germany. ${ }^{6}$ However, the qualification degrees of old generations that were acquired in the former German Democratic Republic may

\footnotetext{
${ }^{5}$ Burda and Hunt (2001) and Hunt (2004) provide empirical evidence for age-selective migration patterns of East-West migration after reunion and discuss the corresponding reasons.

${ }^{6}$ See, for instance, calculations based on the Socio-Economic Panel (SOEP) by Anger and Lupo (2004).
} 
Figure 1: Regional quantile maps for patents per 100 workers, average age, age dispersion and share of high-skilled workers (1995-2008)

(a) Patents per 100 workerss

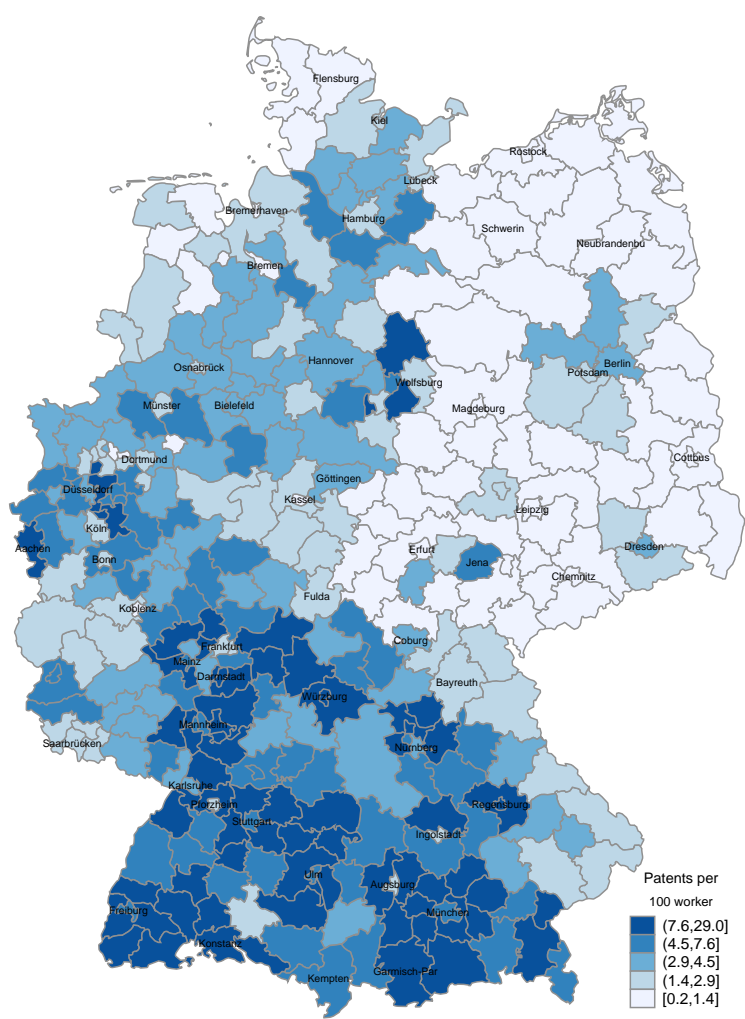

(c) Age dispersion

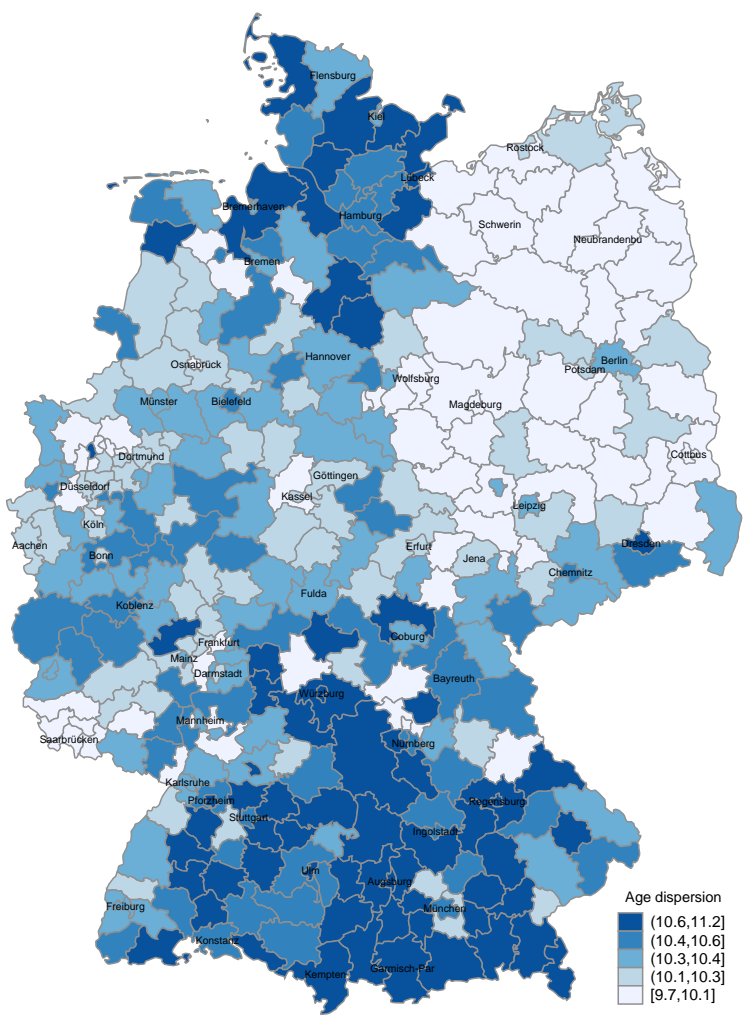

(b) Average age

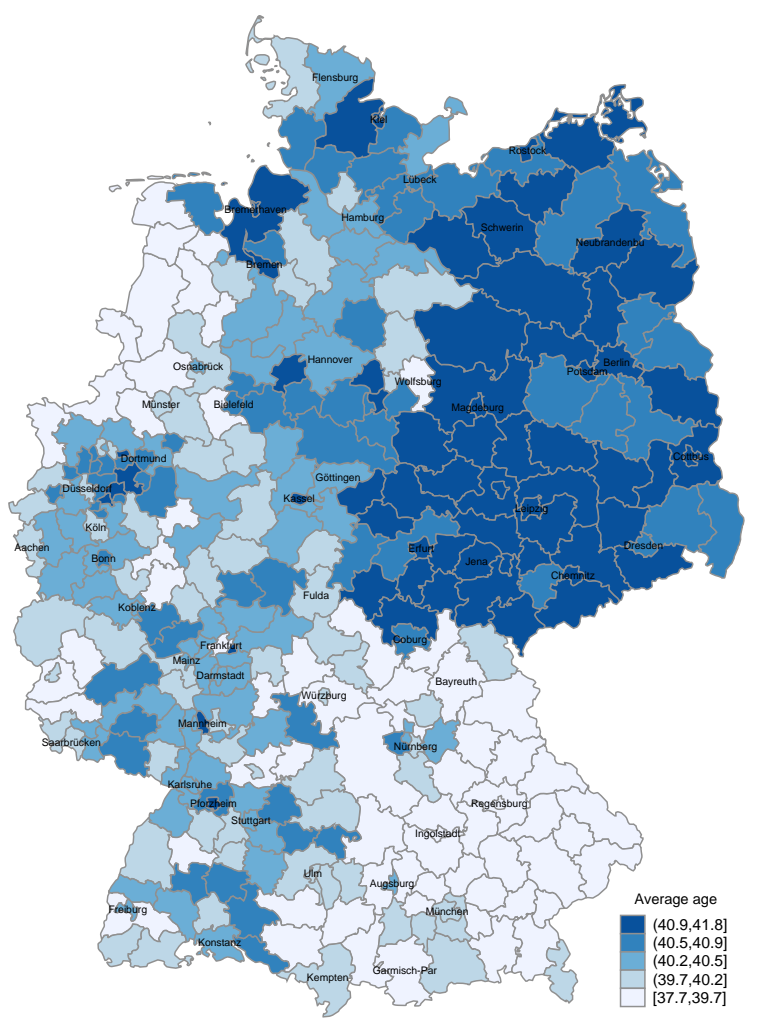

(d) Share of high-skilled

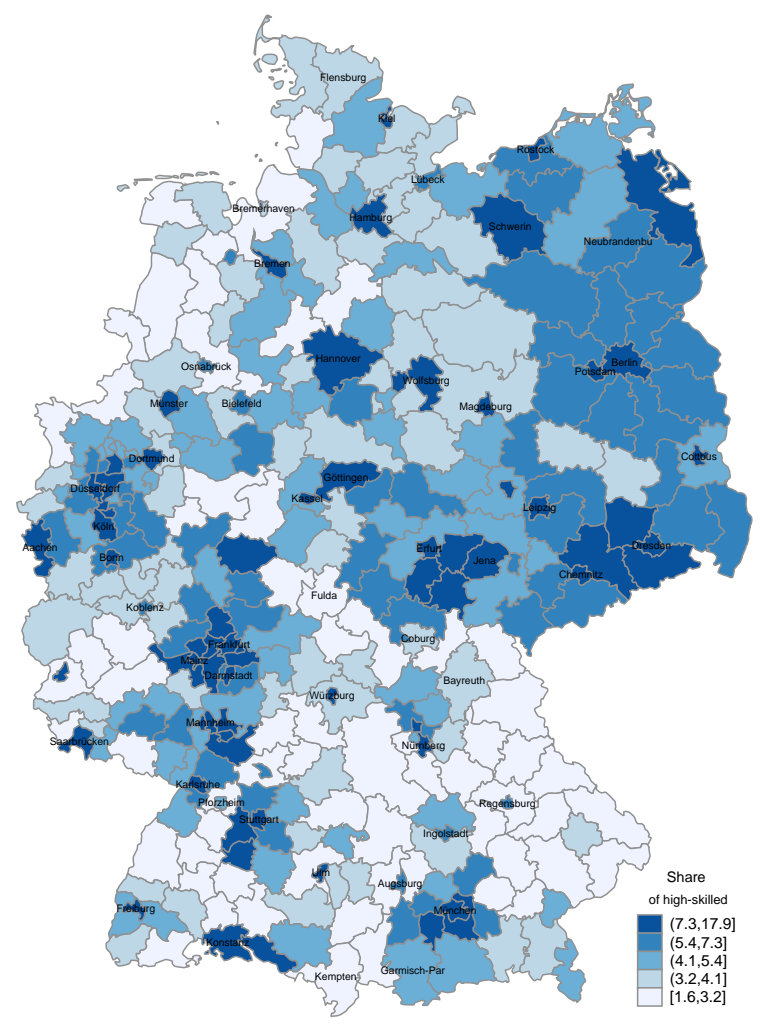


Table 2: Correlation coefficients between patents per 100 workers, average age, age dispersion and share of high-skilled (1995-2008)

\begin{tabular}{lccc}
\hline & $\begin{array}{c}\text { Patents } \\
\text { per 100 workers }\end{array}$ & $\begin{array}{c}\text { Average } \\
\text { age }\end{array}$ & $\begin{array}{c}\text { Age } \\
\text { dispersion }\end{array}$ \\
\hline East Germany (n=65) & & & \\
Patents per 100 workers & 1 & & \\
Average age & $-0.2464^{* *}$ & 1 & \\
Age dispersion & $0.3136^{* *}$ & -0.1518 & 1 \\
Share of high-skilled & $0.5128^{* * *}$ & -0.1542 & $0.3731^{* * *}$ \\
\hline West Germany (n=267) & & & \\
Patents per 100 workers & 1 & & \\
Average age & $-0.1247^{* *}$ & 1 & \\
Age dispersion & $0.1817^{* * *}$ & $-0.1358^{* *}$ & 1 \\
Share of high-skilled & $0.1277^{* *}$ & $0.2407^{* * *}$ & $-0.2484^{* * *}$ \\
\hline
\end{tabular}

Significance levels: $* 10 \%, * * 5 \%, * * * 1 \%$.

not be perfectly comparable to education levels in West Germany.

Table 2 shows correlation coefficients between patent activity and the demographic variables. For their calculation we use the regional averages across the 14-year period similarly to Figure 1 and distinguish between East and West Germany. The correlations show that innovative regions mostly exhibit a low average age and a high age diversity (proxied by age dispersion). This finding could hint at a negative aggregate age-effect as well as an innovation enhancing effect of workforce age diversity. Furthermore, Table 2 indicates a negative correlation between average age and age dispersion, that is regions with older workers coincide with age-homogenous regions. The findings are particularly true for East Germany, where almost all regions without exception are suffering from ageing workforces and low innovation activity. Table 2 also shows that in both parts of the country, regions with a larger share of high-skilled workers produce more patents, although this correlation is higher for East Germany. The reason is that those few regions with mentionable patent applications in East Germany are major cities with high shares of high-skilled workers, whereas the innovators in West Germany are more often located in urban and rural counties with lower skill shares. Overall, the summary statistics reveal large variation across regions for the investigated variables and give first indications of spatial associations that will be analysed explicitly in Section 3. Moreover, simple correlations indicate that areas of high patent activity tend to have an old and age-heterogenous workforce and, at least for West Germany regions, a larger share of high-skilled workers. For this reason, we will focus on the co-evolution of these variables and their spatial regimes in the spatial descriptive analyses. 


\section{Exploratory Space-Time Data Analysis}

In the present section we conduct an Exploratory Space-Time Data Analysis (ESTDA) in order to describe and visualize the spatial distribution of the data. In particular, we aim to identify patterns of spatial clusters, spatial outliers and uncover space-time dynamics. For this perpose, we first test the hypothesis of spatial randomness by using the global Moran' I (MI) statistic (Section 3.1). We also use Local Indicators of Spatial Association (LISA) to investigate and visualize local patterns of spatial associations (clusters). Secondly, we analyse space-time dynamics of the observed spatial associations (Section 3.2) using spatial drift maps and directional MI scatterplots that reveal movements of clusters over time and space to explore a potential strengthening (weakening) of spatial clustering or polarization tendencies. Finally, we calculate LISA transition matrices in order to gain a deeper insight into the stability of the spatial distributions. During the entire analysis, we focus on joint patterns and comovements between innovation, age structure and human capital.

\subsection{Global and Local Spatial Autocorrelation}

Since the distribution of workers cannot be expected to be random in space, we first conduct a test for global spatial autocorrelation using the MI indicator which provides a single summary statistic describing the degree of clustering present in spatial data. In particular, it allows implications on whether, for instance, highly (lowly) innovative regions are often surrounded by regions that are also highly (lowly) innovative. This is interesting, since it reflects spatial dependencies, that are induced, for instance, by social interactions and networking between regions. Moreover, it allows to classify regions by type of cluster. Is a certain region part of a hot (cold) spot or rather an outlier in the latter? This information can be used in any regression analysis as a proxy for e.g. knowledge spillovers between regions.

We first define the structure of the spatial relationship by considering a spatial weights matrix based on rook contiguity that assumes the neighbouring relationships between regions by shared borders. ${ }^{7}$ The spatial weights matrix provides information on the spatial proximity between each pair of locations $i$ and $j$. We standardize the weights matrix so that the elements of each row sum to one (row-standardization). The elements of the standardized weights matrix

\footnotetext{
${ }^{7}$ As recently shown in the literature (e.g. see Patuelli et al. 2012), the choice of the spatial weights matrix is often of little importance, since different geography-based matrices tend to have strongly correlated weights (Patuelli et al. 2012). In a regression framework, multiple matrices may be tested ex post, for example by means of Bayesian model comparison (LeSage and Pace 2009).
} 
are defined as follows:

$$
\widetilde{W}_{i j}=\frac{W_{i j}}{\sum_{j=1}^{N} W_{i j}}
$$

where $W_{i j}=1$ if $i$ and $j$ are defined as neighbours and $W_{i j}=0$ if otherwise. The diagonal values of the weights matrix are set to zero. We define the spatial lag of a variable $y_{i}$ in region $i$ as the spatially weighted average value of a variable evaluated at the neighbouring units of the region. We then construct a bivariate scatterplot with standardized values $y_{i}$ on the horizontal axis and their spatial lags $\sum_{j=1}^{N} \widetilde{W}_{i j} y_{i}$ on the vertical axis (Moran Scatterplot, see Figure 2). As a covariance and correlation measure we consider the Moran's I statistic, which constitutes a measure of the overall spatial dependence and is defined as follows:

$$
I=\frac{N}{S_{o}} \frac{\sum_{i=1}^{n} \sum_{j=1}^{n} \widetilde{W}_{i j}\left(y_{i}-\bar{y}\right)\left(y_{j}-\bar{y}\right)}{\sum_{i=1}^{n}\left(y_{i}-\bar{y}\right)^{2}}, \quad i \neq j
$$

where

$$
S_{o}=\sum_{i=1}^{n} \sum_{j=1}^{n} \widetilde{W}_{i j}
$$

The number of observations (regions) is $N$ and $y_{i}$ represents the value of the $i$ th observation as, for instance, the number of patents per 100 worker of region $i$. $S_{o}$ is a scaling factor equal to the sum of all elements of $\widetilde{W}_{i j}$. MI can be interpreted as a regression coefficient resulting from the regression of the spatial lag $\widetilde{W}_{i j} y_{i}$ on $y_{i}$ (Anselin 1996). The expected value for a spatially random distribution is $E(I)=-1 /(N-1)$ which equals -0.003 for the case of 332 regions. Values of $I$ greater (smaller) than $E(I)$ indicate positive (negative) spatial autocorrelation.

Figure 2 shows the Moran Scatterplots for the investigated variables, and Table 3 contains the corresponding MI coefficients. Each of the points in Figure 2 represents a combination of a regions' average value across the time period 1995-2008 and the corresponding value of the spatially weighted neighbours (spatial lag). The values on the $\mathrm{x}$ - and $\mathrm{y}$-axes are standardized so that the vertical and horizontal lines represent the national values and divide the scatterplot into 4 quadrants that correspond to the following four different types of spatial association (anticlockwise from top right): high-high (HH), low-high (LH), low-low (LL) and high-low (HL). For instance, a $\mathrm{HH}$ region exhibits a high number of patents per worker and is surrounded by regions that exhibit a high number of patents as well. Both HH (hot spots) and LL (cold 
Figure 2: Moran's I scatterplot for patents per 100 workers, average age, age dispersion and share of high-skilled (1995-2008)

(a) Patents per 100 workers

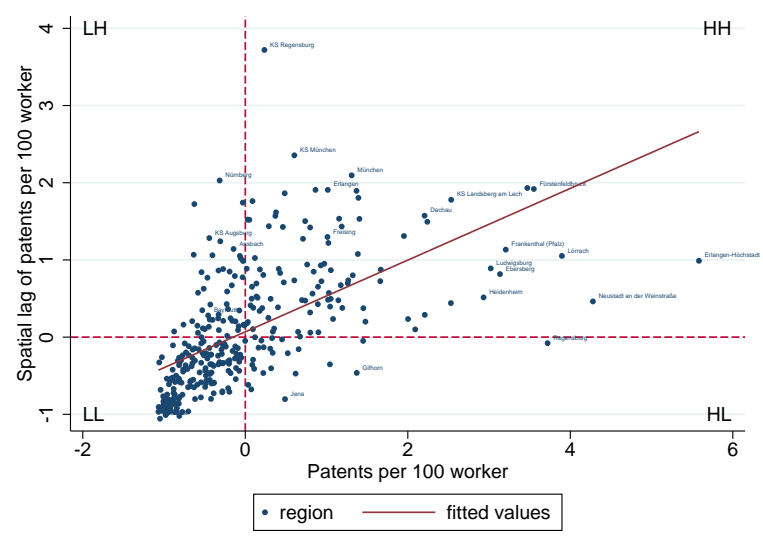

(c) Age dispersion

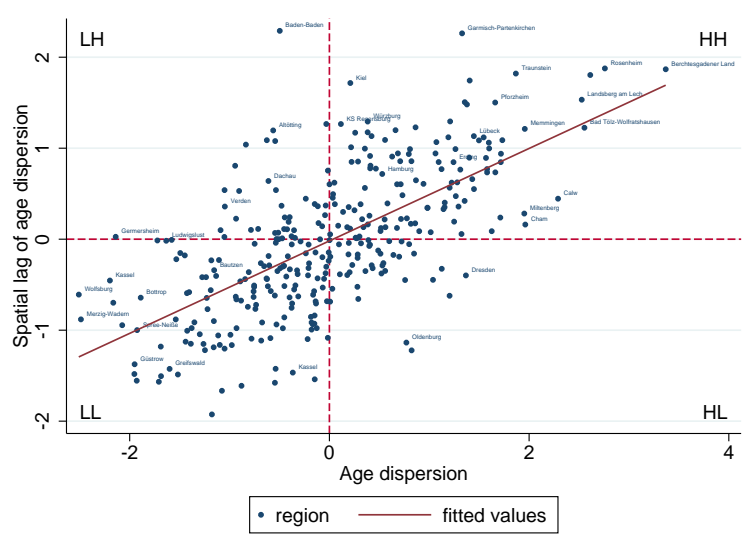

(b) Average age

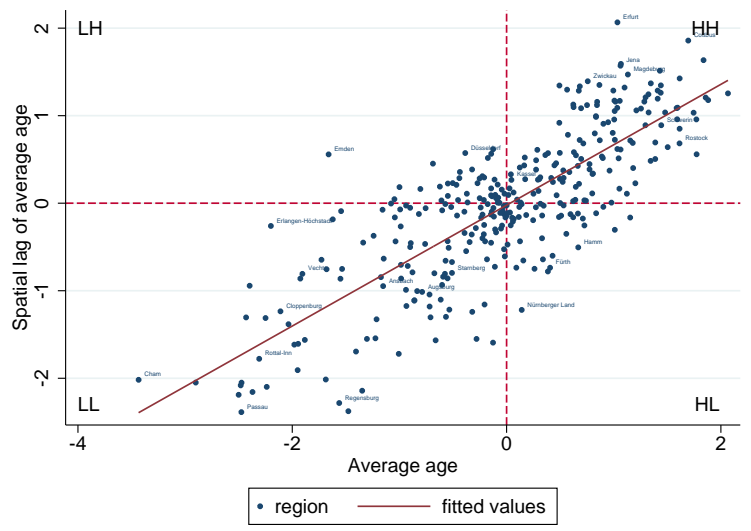

(d) Share of high-skilled

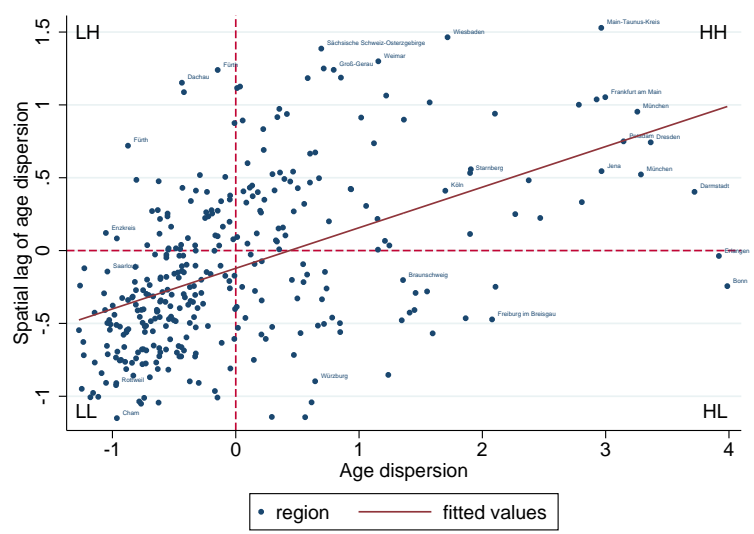

spots) represent regimes of positive spatial association, whereas LH and HL indicate negative association. The calculated MI for global autocorrelation is represented by the slope of the line interpolating all points in the scatterplot since it is based on standardized values.

Figure 3 shows that all variables show a high and significant degree of spatial autocorrelation. Most regions are either in the first or third quadrant. For instance, for patents per worker 98 regions fall into the first quadrant and 160 in the third (the last row in Table 4 summarizes the total amount of regions in each quadrant). Interestingly, the points agglomerate dominantly in the third quadrant and become more dispersed with increasing values. This result indicates that large clusters of scarcely productive regions exist in terms of innovation, whereas clusters of highly productive regions seem rare. A clearer picture is found for average age, for which positive spatial association appears to be wide, in terms of both higher and lower values. According to Column 5 in Table 4, 130 regions fall into the first quadrant and 122 into the third. The pattern 
Table 3: MI Coefficients for patents per 100 workers, average age, age dispersion and share of high-skilled (1995-2008)

\begin{tabular}{lcccc}
\hline & $\mathrm{I}$ & $\mathrm{sd}(\mathrm{I})$ & $\mathrm{z}$ & $\mathrm{p}$-value \\
\hline Patents per 100 workers & 0.473 & 0.037 & 12.737 & 0.000 \\
Average age & 0.691 & 0.038 & 18.417 & 0.000 \\
Age dispersion & 0.508 & 0.038 & 13.572 & 0.000 \\
Share of high-skilled & 0.282 & 0.038 & 7.592 & 0.000 \\
\hline
\end{tabular}

is similar for age dispersion, thus indicating clustering tendencies as well as first evidence for a divide across German regions. These observed patterns are statistically significant according to the MI coefficients shown in Table 3, which are all above zero. For the share of high-skilled workers, spatial clustering seems to play a less important role. In fact, the MI coefficient is much lower than for the other variables. This difference is to be attributed to the different type of spatial pattern of the share of high-skilled, which, as seen in Figure 1, is mostly due to concentration at the metropolitan level, and only in part an East-West Germany issue.

So far, we have detected general tendencies towards clustering with respect to the variables of interest. However, where are these clusters located and what is their spatial extent? Since these questions cannot be answered by means of global measures of spatial autocorrelation, we use Local Indicators of Spatial Association (LISA) as proposed by Anselin (1995). The local version of MI gives an indication on the significance of local spatial clustering for each region $i$ and is defined as follows:

$$
I_{i}=\frac{\sum_{j=1}^{N} \widetilde{W}_{i j}\left(y_{i}-\bar{y}\right)\left(y_{j}-\bar{y}\right)}{\frac{1}{N} \sum_{j=1}^{n}\left(y_{i}-\bar{y}\right)} .
$$

Similarly to the global MI statistic, significance can be determined through the expected value and variance. The interpretation is similar. A positive $I_{i}$ indicates clustering of $\mathrm{HH}$ or LL values in and around $i$, whereas a negative $I_{i}$ indicates a spatial outlier, that is either HL or LH. Figure 3 shows the LISA cluster maps that depict the spatial distribution of the four categories and where only those values that are significant at the 5 per cent level are presented. The maps show large clusters of lowly innovative regions in rural and sparsely populated counties in East Germany around the cities Rostock, Magdeburg, Leipzip, Chemnitz and Cottbus. In contrast, the innovation hubs are located in urban and rural counties in West and South Germany around Cologne, Darmstadt, Mannheim, Stuttgart, Freiburg, Nuremberg and Munich. There is almost no significant outlier, indicating that regions are unlikely to be a high (low) innovative region 
in a low (high) innovative cluster.

Looking at the LISA cluster maps for average age and age dispersion shows a large cluster of old and homogenous regions in East Germany. This area has been suffering from out-migration and unfavorable economic perspectives since reunification. Considering West Germany, there is only one old age cluster in the ruhr district that has been struggling with its structural change, whereas almost all Bavarian regions in South Germany comprise one large cluster of young age regions. Famous universities and good job perspectives has helped these regions to hold and further attract young workers. Clusters of regions with a high age diversity are mainly located in South Germany between Stuttgart, Nuremberg and Munich and in North Germany around Hamburg. Similar to innovation, outliers are rare on the demographic landscape.

The LISA cluster maps for the share of high-skilled reveals clusters of highly educated workers in cities with popular universities such as Cologne, Frankfurt, Mannheim, Stuttgart and Munich in West Germany and Berlin, Dresden, Chemnitz and Jena in East Germany. However, the map also shows a large strip of regions with lowly educated workers in South Germany around Nueremberg and Regensburg. These regions are mostly rural regions with good job perspectives for particularly low qualified workers.

We can now discuss the evidence shown in Figure 5 also from a numerical point of view. As discussed in Section 1, the workforce composition may be expected to impact the innovativeness of local firms negatively through a higher average age, lower age diversity and a lower skill composition. If this is the case, we would expect lowly innovative clusters to be associated, for instance, with clusters of old, homogeneous and less educated workers. To investigate this question, we construct contingency tables in Table 4 that show two-way tables of frequency counts for the number of regions by type of spatial cluster (HH, LL) or outlier (HL, LH). It should be noted here that Table 4 includes all regions, that is also those regions for which the local MI coefficient is insignificant. For instance, the number 98 in row (4) and column (1) means that 98 lowly innovative regions are, at the same time, part of clusters with above average ages. As a measure of statistical association we use Pearson's $\chi^{2}$ test, which relies on the hypothesis that the rows and columns in the two-way table are independent.

For all variables, Table 4 indicates a strong association with patent production as the Pearson's $\chi^{2}$ test is rejected in all cases. In particular, our figures hint at an association between clusters of young and age-heterogenous workers. The relationship between innovation and highskilled workers is less clear. Although 77 regions belonging to clusters with low shares of high- 
Figure 3: LISA cluster maps for patents per 100 workers, average age, age dispersion and share of high-skilled (1995-2008)

(a) Patents per 100 workers

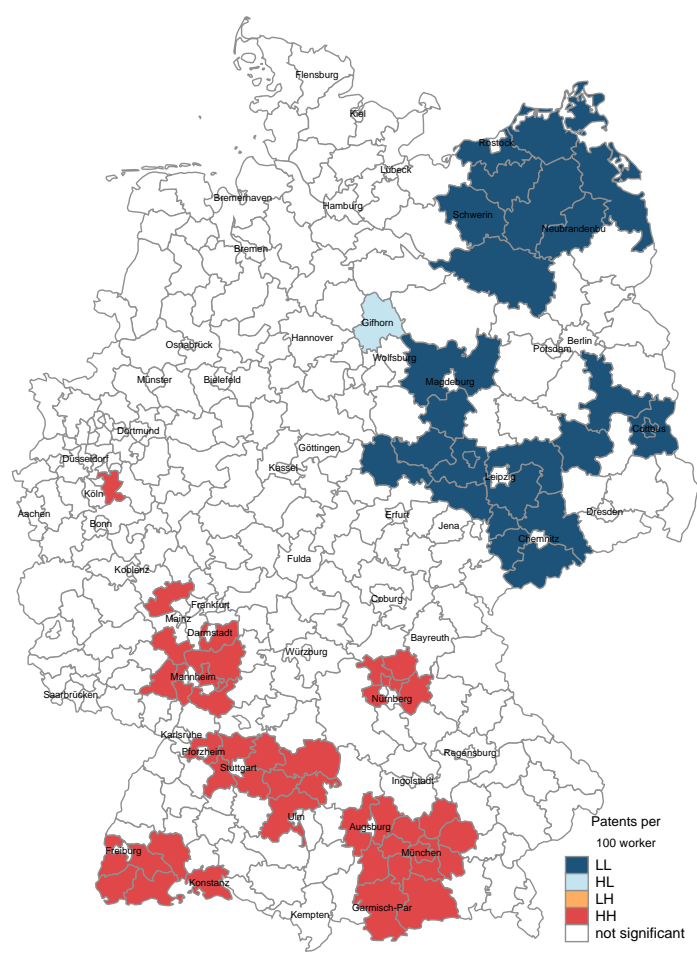

(c) Age dispersion

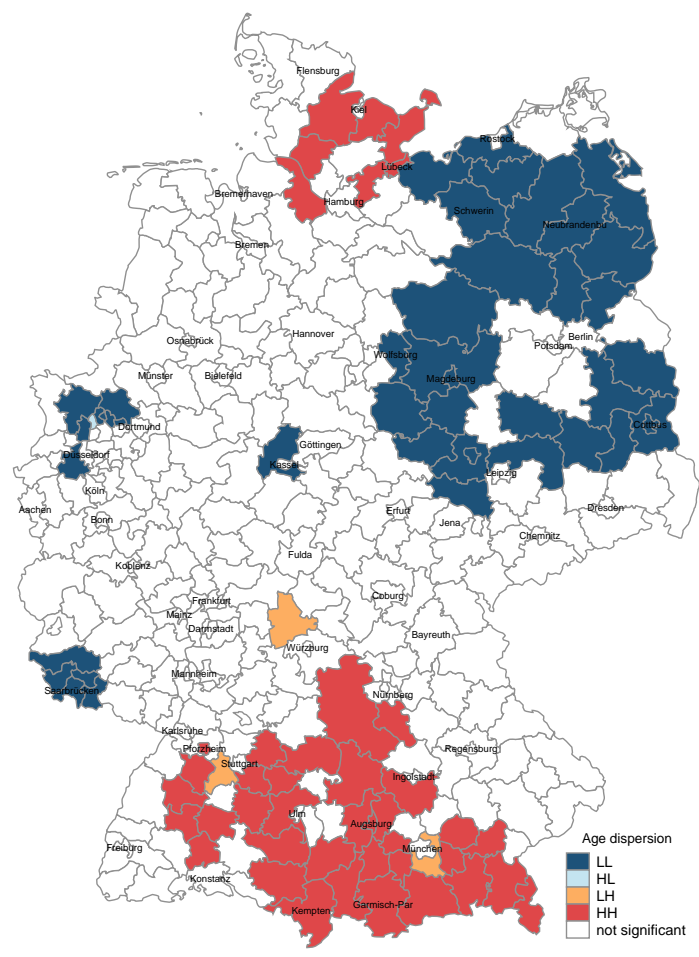

(b) Average age

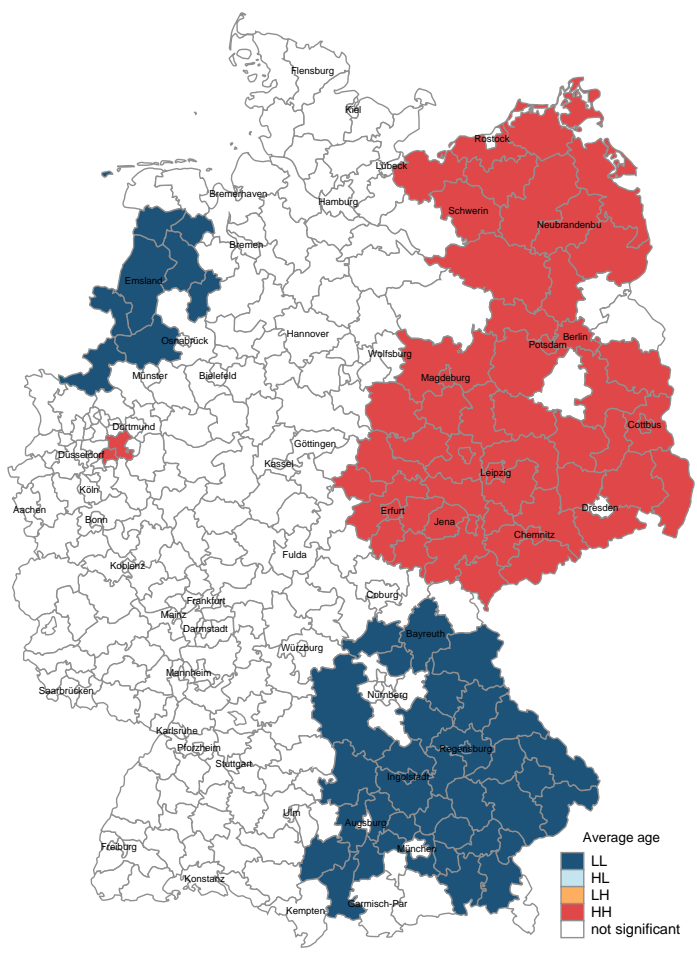

(d) Share of high-skilled

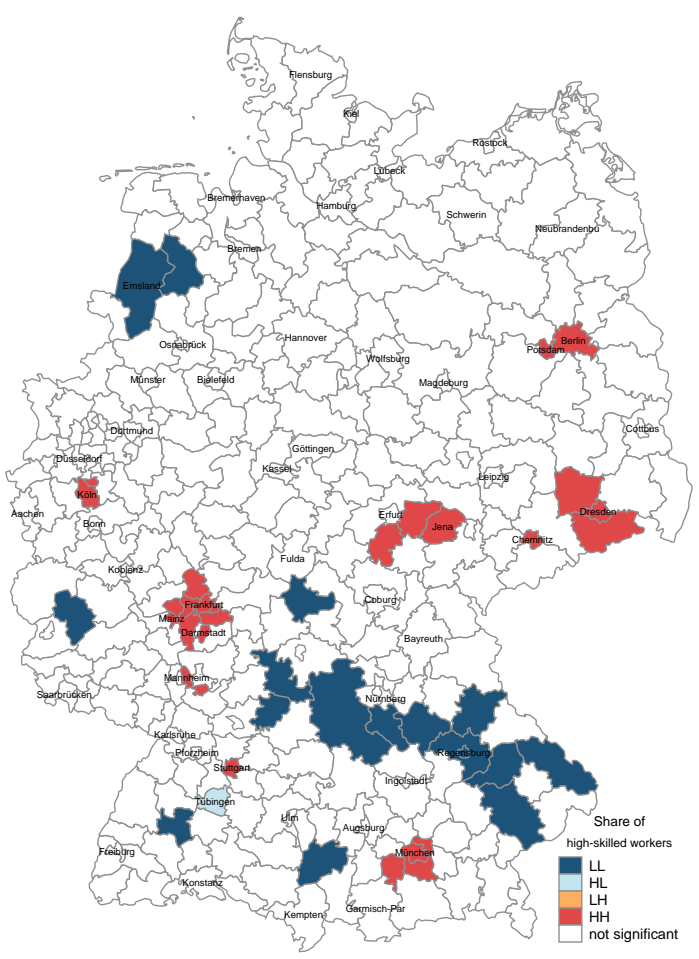

skilled workers are at the same time part of a lowly innovative cluster, the opposite is not exactly true. These ambiguous results are partly driven by lowly innovative (despite being highly ed- 
Table 4: Contingency tables between innovation and demographic cluster/outlier types

\begin{tabular}{|c|c|c|c|c|c|c|}
\hline Variable & $\begin{array}{l}\text { Cluster/Outlier } \\
\text { type }\end{array}$ & $\begin{array}{l}\quad \text { P } \\
\text { High-High }\end{array}$ & $\begin{array}{c}\text { tents per } \\
\quad(2) \\
\text { Low-High }\end{array}$ & $\begin{array}{c}00 \text { worke } \\
(3) \\
\text { High-Low }\end{array}$ & $\begin{array}{c}(4) \\
\text { Low-Low }\end{array}$ & $\begin{array}{c}(5) \\
\text { Total obs. }\end{array}$ \\
\hline $\begin{array}{l}\text { Average } \\
\text { age }\end{array}$ & $\begin{array}{l}\text { High-High } \\
\text { Low-High } \\
\text { High-Low } \\
\text { Low-Low }\end{array}$ & $\begin{array}{l}13 \\
12 \\
21 \\
52 \\
\quad \text { Pear }\end{array}$ & $\begin{array}{c}10 \\
7 \\
8 \\
26 \\
\text { on } \chi^{2}=76\end{array}$ & $\begin{array}{c}9 \\
4 \\
0 \\
10 \\
1687 \mathrm{Pr}=0\end{array}$ & $\begin{array}{r}98 \\
16 \\
12 \\
34 \\
000\end{array}$ & $\begin{array}{c}130 \\
39 \\
41 \\
122\end{array}$ \\
\hline $\begin{array}{l}\text { Age } \\
\text { dispersion }\end{array}$ & $\begin{array}{l}\text { High-High } \\
\text { Low-High } \\
\text { High-Low } \\
\text { Low-Low }\end{array}$ & $\begin{array}{l}55 \\
16 \\
9 \\
18 \\
\quad \text { Pear }\end{array}$ & $\begin{array}{c}21 \\
8 \\
8 \\
14 \\
\text { on } \chi^{2}=54\end{array}$ & $\begin{array}{c}7 \\
4 \\
2 \\
10 \\
235 \mathrm{Pr}=0\end{array}$ & $\begin{array}{r}34 \\
12 \\
22 \\
92 \\
000\end{array}$ & $\begin{array}{c}117 \\
40 \\
41 \\
134\end{array}$ \\
\hline $\begin{array}{l}\text { Share of } \\
\text { high-skilled }\end{array}$ & $\begin{array}{l}\text { High-High } \\
\text { Low-High } \\
\text { High-Low } \\
\text { Low-Low }\end{array}$ & $\begin{array}{c}31 \\
16 \\
8 \\
43 \\
\quad \text { Pear }\end{array}$ & $\begin{array}{c}9 \\
5 \\
9 \\
28 \\
\text { on } \chi^{2}=10\end{array}$ & $\begin{array}{c}3 \\
3 \\
3 \\
14 \\
431 \mathrm{Pr}=0\end{array}$ & $\begin{array}{r}38 \\
20 \\
25 \\
77 \\
323\end{array}$ & $\begin{array}{c}81 \\
44 \\
45 \\
162\end{array}$ \\
\hline & Total obs. & 98 & 51 & 23 & 160 & 332 \\
\hline
\end{tabular}

ucated) regions in East Germany. Also, innovative regions in West Germany are often urban counties with lower shares of high-skilled workers, compared to major cities.

\subsection{Space-Time Dynamics}

So far, we have gained insights into the spatial dimension of the regional distributions, measured by average values across the time period 1995-2008. We are now interested in how the distributions evolved over time. Are there any observable time trends? How stable are the observed spatial patterns? Most studies that analyse the evolution of a variable's spatial distribution visually compare different geographical maps for separate points in time. Such approaches make it very difficult to analyse relative movements across time and space. For this reason, we apply new methods that are designed to address this limitation.

\subsubsection{Standardised Directional Moran Scatterplots}

In the following section we investigate regional dynamics using Standardized Directional Moran Scatterplots (SDMS, Rey et al. 2011). For each variable, we calculate Moran Scatterplots for the years 1995 and 2008 separately (as described in Section 3.1) using relative values (to the national value). Note, that this time period is particularly interesting, due to the large second wave of selective migrants that moved from East to West Germany during the end 90ties after 
Figure 4: Standardized directional moran scatterplots for patents per 100 workers, average age, age dispersion and share of high-skilled (1995 to 2008)

(a) Patents per 100 workers

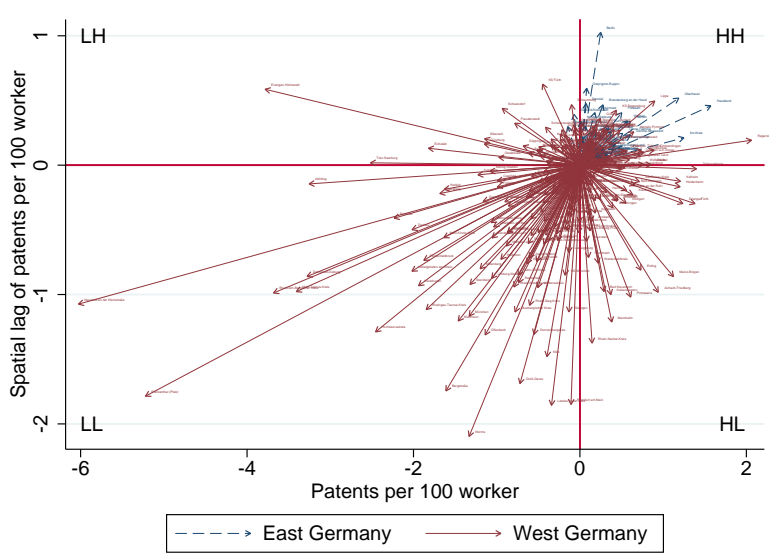

(c) Age dispersion

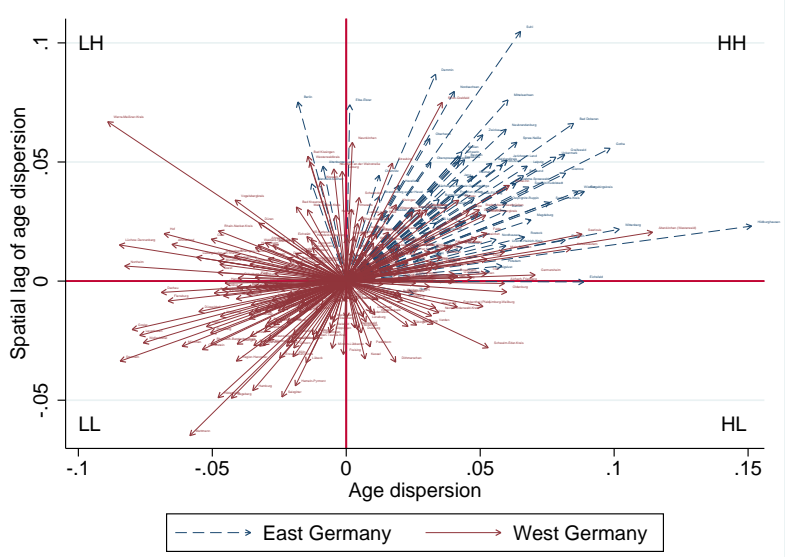

(b) Average age

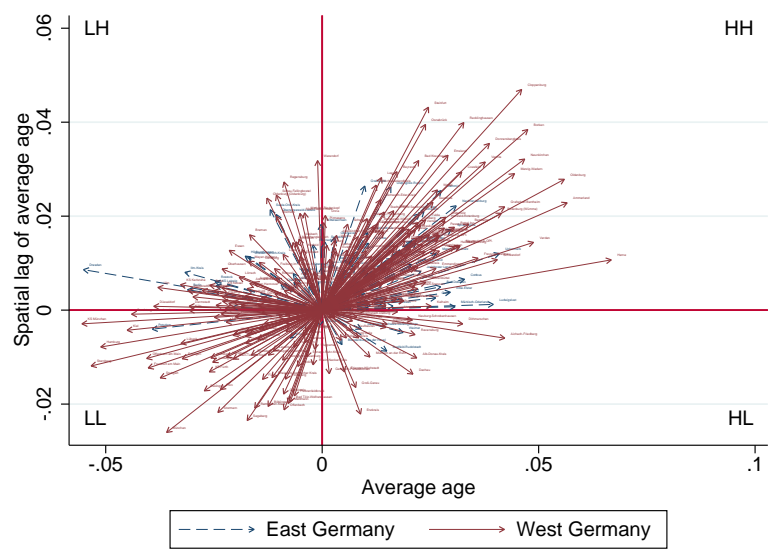

(d) Share of high-skilled

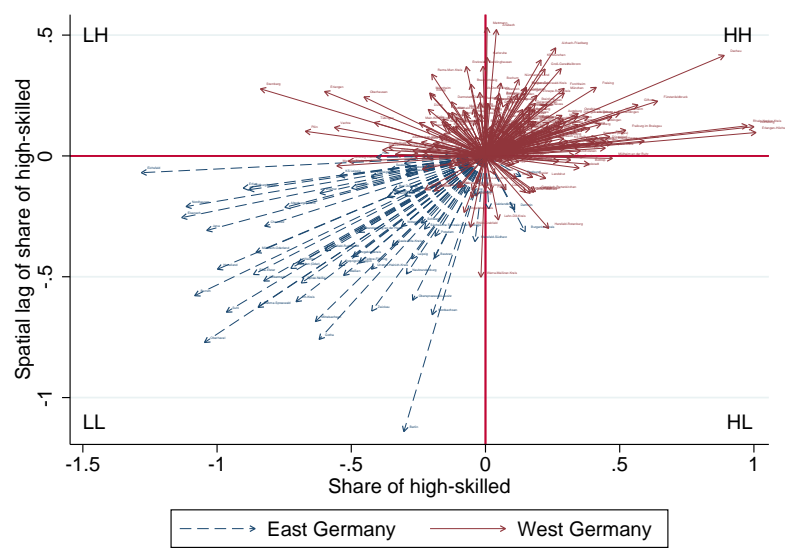

reunification(see Arntz et. al 2011). This wave of migrants took its peak in 2001 and is expected to have changed the regional distribution of workforce age structure. We then plot each region's value in 1995 and 2008 into the same Scatterplot and connect both points to receive directional movement vectors. We normalize all vectors by the national value in 1995 to produce the SDMS shown in Figure 4. Whereas the arrowheads point to the regions' relative value in 2008, the vectors' starting point (at the origin) represents the regions' relative value in 1995. The SDMS thus captures how a regions' relative value developed between 1995 and 2008. For instance, a relative move of a region towards the first $(\mathrm{HH})$ or third quadrant (LL) reflects the strengthening or emergence of positive spatial clustering, whereas movements towards the second (LH) or fourth (HL) quadrant reflect negative clustering (i.e. local divergence process). The longer the movement vector, the larger the relative movement compared to the mean.

Figure 4 shows the SDMS for our four variables. Movements of East German regions are 
shown in blue, and West German regions are represented by the colour red. Interestingly, for all investigated variables the SDMS show dominant movements to the first $(\mathrm{HH})$ and third (LL) quadrant, i.e. we observe tendencies towards positive clustering. Overall, the patterns speak in favour of a polarization trend among German regions where some regions develop in a favourable way, whereas other regions' relative position deteriorates. The specific patterns are discussed in the following. In particular, the average size of movements (length of the arrow) for patents per 100 worker is much greater compared to the other variables, indicating that patent activity varies to a greater extent over time. In particular, East German regions including mostly rural regions around the cities Berlin, Potsdam (e.g. Overhavel, Havelland, Barnim, Teltow-Fläming and Dahme-Spreewald) and Jena (e.g. Weimar and Ilm) have improved in terms of innovation production. However, the movements are small, reflecting low dynamics in East Germany and low levels of innovation activity overall. In West Germany, the picture is mixed. Even though some regions have moved towards the first quadrant, tendencies towards cold spots (movements towards the third quadrant) are pronounced as well, particular among rural West German regions. Nevertheless, some of these regions are moving from high initial values such as Neustadt an der Weinstraße, Frankenthal and Darmstadt-Dieburg.

Looking at average age shows that dominant movement towards the first quadrant are driven by mostly rural regions both in East and West Germany. In contrast, regions moving towards the third quadrant mostly include major West German cities such as Munich, Stuttgart, Frankfurt, Hamburg. The result shows that cities are becoming more important for young workers, whereas rural regions are increasingly losing its youngest workers.

Another interesting observation can be made for age dispersion and the share of highly skilled workers. We observe that most East German regions are moving in the direction of a stronger clustering of more heterogenous age values and lower human capital. In contrast, West German regions appear to be partly moving in the opposite direction (less heterogeneity and higher skills). The development for the share of high-skilled reflects skill-selective East-West migration patterns during the observed period, which has been found, for instance, by Arntz et al. (2011).

In order to study potential comovements of the investigated variables, we construct contingency tables for movement types in the SDMS similar to Table 4. As found above, in Table 5, the Pearson $\chi^{2}$ test on independence is rejected in all cases. The table reads as follows. The value in row (4) and column (1) indicates 63 positive comovements to $\mathrm{HH}$ for average age and 
Table 5: Contingency tables between types of movements in the directional scatterplot

\begin{tabular}{|c|c|c|c|c|c|c|}
\hline Variable & $\begin{array}{l}\text { Movements } \\
\text { towards a } \\
\text { Cluster/Outlier } \\
\text { type }\end{array}$ & $\begin{array}{c}(1) \\
\text { High-High }\end{array}$ & $\begin{array}{r}\text { Patent } \\
(2) \\
\text { Low-High }\end{array}$ & $\begin{array}{l}\text { per } 100 \text { v } \\
\quad(3) \\
\text { High-Low }\end{array}$ & $\begin{array}{l}\text { orkers } \\
\qquad \begin{array}{l}(4) \\
\text { Low-Low }\end{array}\end{array}$ & $\begin{array}{c}(5) \\
\text { Total obs. }\end{array}$ \\
\hline $\begin{array}{l}\text { Average } \\
\text { age }\end{array}$ & $\begin{array}{l}\text { High-High } \\
\text { Low-High } \\
\text { High-Low } \\
\text { Low-Low }\end{array}$ & $\begin{array}{c}63 \\
27 \\
5 \\
15 \\
\quad \text { Pea }\end{array}$ & $\begin{array}{c}30 \\
14 \\
5 \\
9 \\
\chi^{2}=20\end{array}$ & $\begin{array}{c}24 \\
15 \\
7 \\
11 \\
1743 \mathrm{Pr}=0\end{array}$ & $\begin{array}{r}44 \\
17 \\
10 \\
35 \\
317\end{array}$ & $\begin{array}{c}161 \\
73 \\
27 \\
70\end{array}$ \\
\hline $\begin{array}{l}\text { Age } \\
\text { dispersion }\end{array}$ & $\begin{array}{l}\text { High-High } \\
\text { Low-High } \\
\text { High-Low } \\
\text { Low-Low }\end{array}$ & $\begin{array}{l}70 \\
9 \\
5 \\
26 \\
\quad \text { Pea }\end{array}$ & $\begin{array}{c}20 \\
8 \\
9 \\
21 \\
\chi^{2}=43\end{array}$ & $\begin{array}{c}15 \\
18 \\
6 \\
18 \\
184 \mathrm{Pr}=0\end{array}$ & $\begin{array}{r}33 \\
\\
18 \\
18 \\
\\
37 \\
000\end{array}$ & $\begin{array}{c}138 \\
53 \\
38 \\
102\end{array}$ \\
\hline $\begin{array}{l}\text { Share of } \\
\text { high-skilled }\end{array}$ & $\begin{array}{l}\text { High-High } \\
\text { Low-High } \\
\text { High-Low } \\
\text { Low-Low }\end{array}$ & $\begin{array}{c}31 \\
12 \\
5 \\
62 \\
\quad \text { Pear }\end{array}$ & $\begin{array}{c}24 \\
15 \\
9 \\
10 \\
\text { on } \chi^{2}=84 \\
58\end{array}$ & $\begin{array}{c}27 \\
17 \\
9 \\
4 \\
773 \mathrm{Pr}=0 \\
57\end{array}$ & $\begin{array}{r}58 \\
29 \\
8 \\
11 \\
000 \\
\end{array}$ & $\begin{array}{c}140 \\
73 \\
31 \\
87\end{array}$ \\
\hline
\end{tabular}

innovation, while row (4) and column (4) tell us that we observe 35 negative comovements to LL. This result is somehow surprising, since we would expect the evolution of innovation clusters to coincide with the evolution of young rather than old workers. However, the figures show low innovative East German regions that have been relatively improving their innovation output, despite an ageing workforce and low economic performance. The figures also indicate that 44 mostly West German regions have been moving both towards lowly innovative and high-age clusters. For age diversity, the results reflect that an increase in the clustering of age-heterogenous (homogenous) regions coincides largely with an increase in the clustering of highly (lowly) innovative regions. These positive comovements hint at a positive relationship between age diversity and a regions' capability to innovate as has been found by many firm-level studies. The mostly opposite movements of innovation and workers' skills may reflect the positive relationship between the latter variable and workers' age (although workers' skills are more concentrated in major cities), suggesting that if both variables were used in a regression framework, appropriate diagnostics should be carried out to identify potential issues of collinearity.

One disadvantage of the SDMSs is that they hardly allow to infer how the clustering tendencies and polarization trends are developing from a geographical point of view (e.g., in NorthSouth and East-West terms). In order to see how specific geographical patterns (e.g. the 
well-known East-West divide) evolve over time, we construct spatial drift maps in the following section. Such analysis allows us to complement the above spatio-temporal results, by showing whether change over time in the variables analysed leads to higher or lower concentration along the main directions (North-South, East-West).

\subsubsection{Spatial Drift Maps}

In what follows, we construct spatial drift maps (SDM) for the investigated variables as described by Laurent et. al (2012) and originally developed by Cressie (1993). The maps are constructed as follows. First, we interpose a grid on the map of German regions. Second, we compute the mean and median of each grid row and column, and plot the values of the selected variables in two separate graphs, using alternatively the $\mathrm{x}$ and $\mathrm{y}$ axis, while maintaining each region centroid's latitude and longitude, respectively. Connecting - in each graph - the means (or medians) by row or by column should result, in the case of random spatial distribution, in a vertical and a horizontal line, respectively. Differences between the mean (bold) and median (dotted) lines indicate the presence of outliers.

Figure 5 shows the SDMs for each of the four variables for both years 1995 and 2008 separately. Looking first at the vertical line of patents per 100 worker in 1995 (Figure 5, top left) shows a drift to the left when moving North. This means that the north part of Germany is less productive than the south part regarding innovation. For the same year, the horizontal line shows a drift to the bottom when moving East. This indicates that West German regions generate more patents per worker than East German regions. Thus, we confirm the former findings suggesting a East-West and North-South divide with respect to innovation performance. More interestingly, we compare the drift maps of the years 1995 and 2008 and find no significant overall change in spatial distribution, except that the amount of outliers is lower. This finding may reflect regions absorbing the characteristics of its neighbours.

Considering the SDM for average age in 1995, we observe a drift to the right when moving North. At the same time, we find that average age increases when moving East, although some South German regions follow the opposite pattern. The finding again confirms the East-West and North-South divide with respect to the average age. Moreover, the development between 1995 and 2008 shows that the average age has increased (strong rightward shift of the distribution). Also, the vertical line has become slightly more straight, whereas the horizontal line shows a upward drift. This development reflects East German regions that have been ageing faster than 
Figure 5: Spatial drift maps for patents per 100 workers, average age, age dispersion and share of high-skilled $(1995,2008)$

(a) Patents per 100 workers
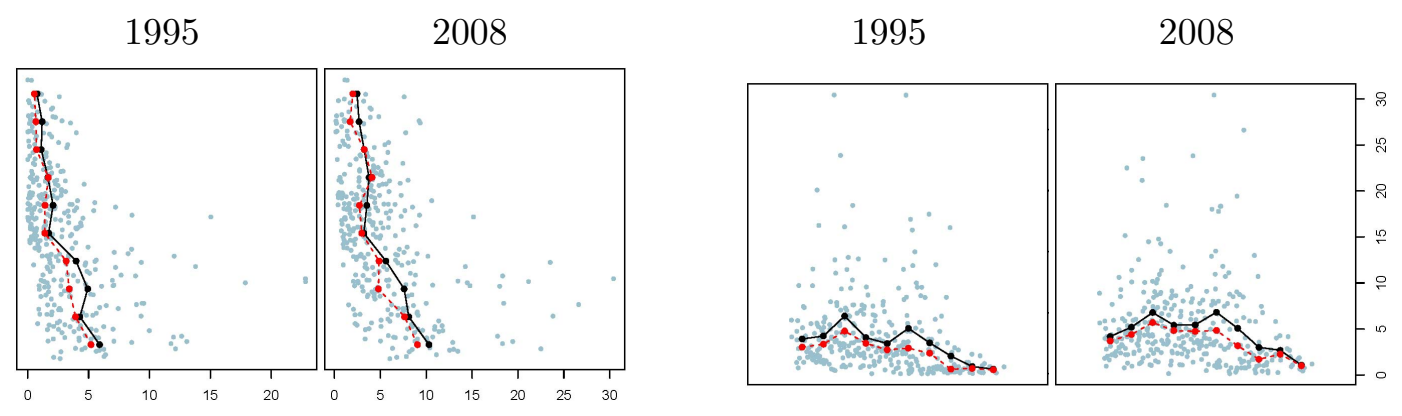

(b) Average age
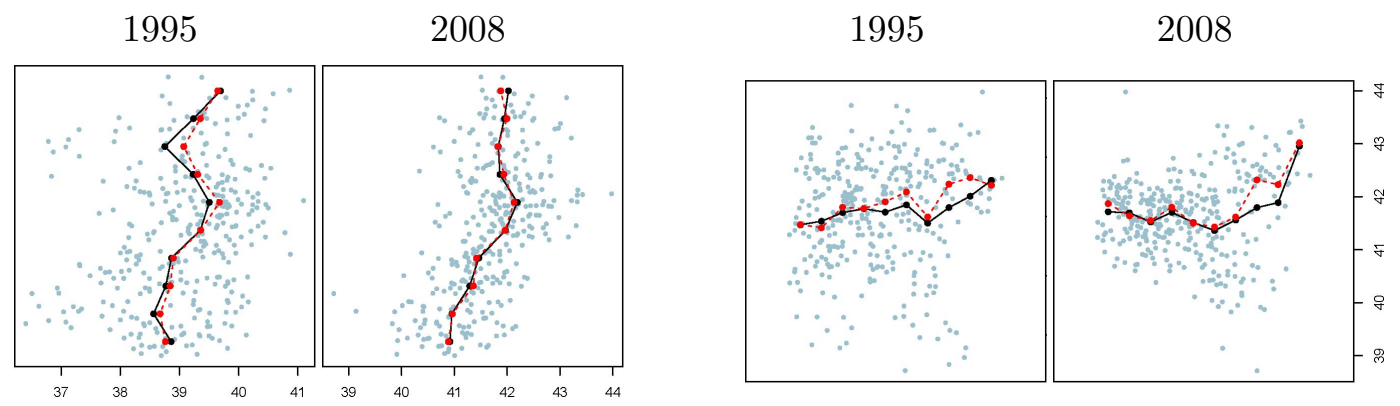

(c) Age dispersion
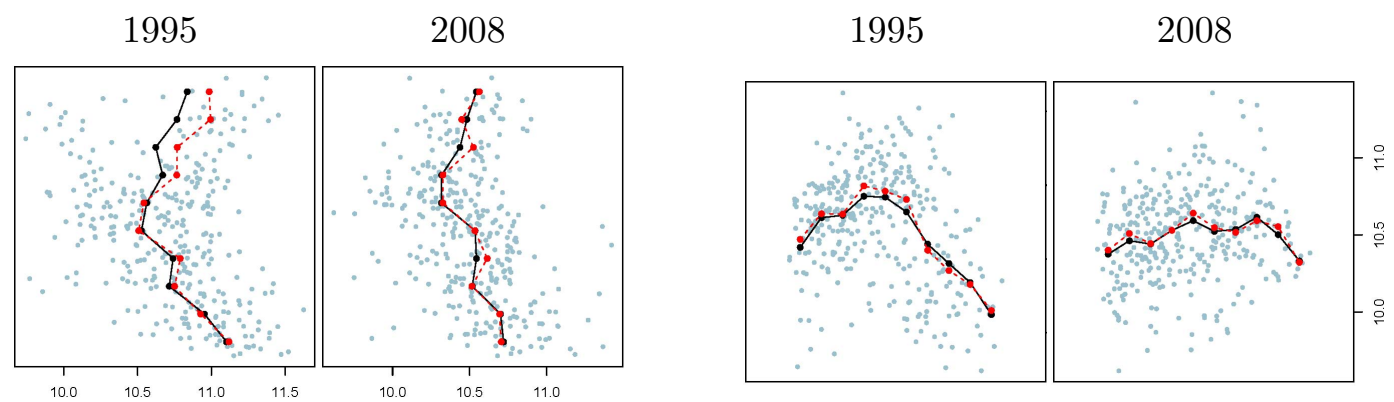

(d) Share of high-skilled
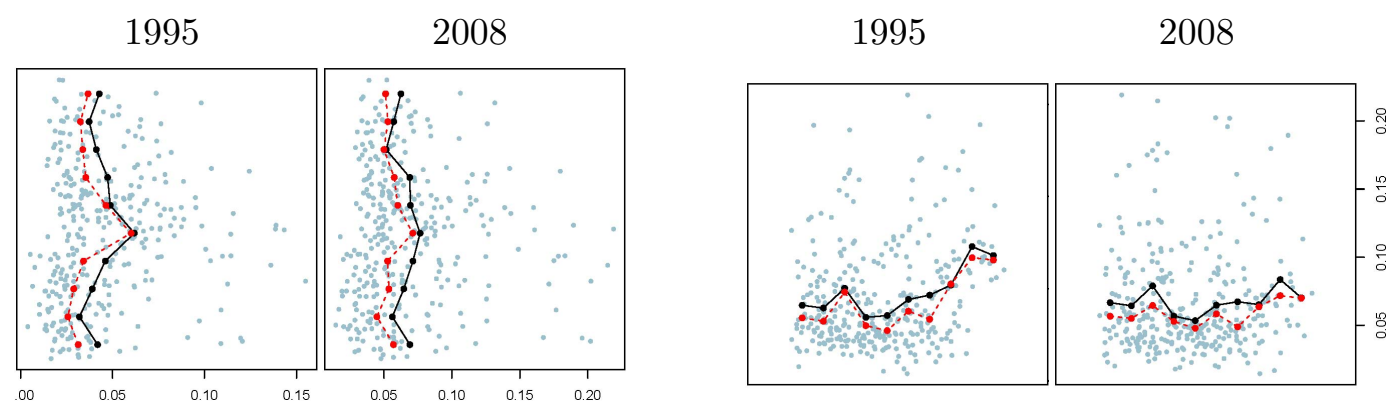

West German regions, on average. Again, outliers have become less important. Thus, the divide in average age of workers has increased between East and West Germany. 
The graph for the age dispersion shows a rightward drift when moving South and downward shift when moving East, reflecting young and heterogenous regions in the South and mostly old and homogenous regions in East Germany. Comparing the years 1995 and 2008 indicates that the spatial heterogeneity and the curvature of the means interpolation has decreased. The pattern can be explained by the rightward shift in the age distribution, as discussed in Section 3.2.1. Therefore, interestingly, East and West Germany have become similar in their age diversity.

For the share of highly skilled workers, only a central drift can be observed for the vertical line in 1995, which is mostly reabsorbed in 2008. The horizontal line shows an upward drift in 1995 as well, suggesting that the East German regions tend to have accumulated more human capital. Comparing the lines for 1995 and 2008 shows that these outliers (as for the vertical line) have greatly decreased and the East-West divide has disappeared. The reason for the latter development lies, as mentioned in Section 3.2.1, in (retirement of older workers and) skill-selective out-migration from East to West Germany that took place during the observation period. Despite reservations against the comparability of the skills levels (as well as any other human capital variable), the results indicate that East and West Germany have become more similar in terms of their skill composition.

We have so far gained insights into the geographical patterns and dynamics of the investigated variables. We now investigate the stability of these patterns over time by looking at the probability for region to remain in the same state or to reverse the trend. For this, we look at LISA transition probabilities in the next section.

\subsubsection{Space-Time Transitions}

In this section we calculate LISA transition matrices in order to track the evolution of the investigated variables from a spatial clustering perspective. The method is based on the classical Markov chain approach, which allows to study regional dynamics between different groups (or quantiles). In this respect, from a methodological viewpoint, the proposed LISA transition matrices are obtained similarly to the standard probability transition matrices. We follow Rey (2001) and investigate the transitions of regions between the four different types of spatial association outlined earlier (HH, LH, HL, LL). First, we specify a state probability vector $P_{t}=$ $\left[P_{1 t}, P_{2 t}, P_{3 t}, P_{4 t}\right]$ that represents the probability of a region to be in one of the four states in period $t$, where $t=1,2, \ldots, 14$ in our case. We then define a $4 \times 4$ transition probability matrix, $\mathbf{M}=\left[m_{i j t}\right]$, showing the likelihood of a region to remain in initial state $i$ or to move from state 
Table 6: LISA transition probabilities for patents per 100 workers, average age, age dispersion and share of high-skilled (1995-2008)

\begin{tabular}{|c|c|c|c|c|c|c|c|}
\hline Variable & $\begin{array}{l}\text { Cluster/ } \\
\text { Outlier type } \\
\text { in period } t\end{array}$ & $\begin{array}{l}\text { Cluster } \\
(1) \\
(H H)_{t+1}\end{array}$ & $\begin{array}{c}\text { Outlier ty } \\
(2) \\
(L H)_{t+1}\end{array}$ & $\begin{array}{c}\text { e in perio } \\
(3) \\
(H L)_{t+1}\end{array}$ & $\begin{array}{c}t+1 \\
\quad(4) \\
(L L)_{t+1}\end{array}$ & $\begin{array}{c}(5) \\
\text { Initial shares } \\
\text { in } 1995\end{array}$ & $\begin{array}{c}(6) \\
\text { Steady } \\
\text { state }\end{array}$ \\
\hline \multirow{4}{*}{$\begin{array}{l}\text { Patents per } \\
100 \text { worker }\end{array}$} & $(H H)_{t}$ & 90.3 & 6.3 & 2.9 & 0.5 & 29.5 & 28.3 \\
\hline & $(L H)_{t}$ & 12.1 & 79.6 & 0.2 & 8.1 & 15.4 & 15.6 \\
\hline & $(H L)_{t}$ & 8.4 & 1.9 & 68.9 & 20.7 & 5.7 & 8.0 \\
\hline & $(L L)_{t}$ & 0.4 & 2.6 & 3.4 & 93.6 & 49.4 & 48.1 \\
\hline \multirow[t]{4}{*}{ Average age } & $(H H)_{t}$ & 91.4 & 4.6 & 3.5 & 0.6 & 44.6 & 38.3 \\
\hline & $(L H)_{t}$ & 16.5 & 68.1 & 1.3 & 14.2 & 9.0 & 11.8 \\
\hline & $(H L)_{t}$ & 9.6 & 1.8 & 71.4 & 17.2 & 10.8 & 13.3 \\
\hline & $(L L)_{t}$ & 0.3 & 4.9 & 6.3 & 88.6 & 35.5 & 36.7 \\
\hline \multirow{4}{*}{ Age dispersion } & $(H H)_{t}$ & 82.7 & 8.5 & 7.6 & 1.2 & 45.2 & 29.5 \\
\hline & $(L H)_{t}$ & 17.6 & 63.6 & 3.8 & 15.0 & 13.3 & 13.5 \\
\hline & $(H L)_{t}$ & 12.4 & 2.4 & 66.9 & 18.3 & 11.8 & 17.8 \\
\hline & $(L L)_{t}$ & 1.3 & 5.0 & 8.1 & 85.6 & 29.8 & 39.2 \\
\hline \multirow{4}{*}{$\begin{array}{l}\text { Share of } \\
\text { high-skilled }\end{array}$} & $(H H)_{t}$ & 92.5 & 5.0 & 2.4 & 0.1 & 26.5 & 18.4 \\
\hline & $(L H)_{t}$ & 5.7 & 88.1 & 0.2 & 6.1 & 10.5 & 14.9 \\
\hline & $(H L)_{t}$ & 3.6 & 0.2 & 88.6 & 7.6 & 13.9 & 14.0 \\
\hline & $(L L)_{t}$ & 0.1 & 1.6 & 2.1 & 96.3 & 49.1 & 52.7 \\
\hline
\end{tabular}

$i$ in period $t$ to state $j$ in period $t+1$ during the 14-year period. Transition probabilities are assumed to be time-invariant, that is $m_{i j t}=m_{i j t+b} \forall b$. Given these assumptions, the state probability vector in period $t+b$ can be written as follows:

$$
P_{t+b}=P_{t} \mathbf{M}^{b}
$$

Finally, the limiting transition probabilities yield the ergodic steady-state distribution vector. Formally, this can be expressed as follows:

$$
\mathbf{M}^{T^{0}}=\mathbf{A}
$$

where $\mathbf{A}$ is the steady-state matrix for the system and $T^{0}$ is the number of years required to reach the steady state. The steady-state vector, defined by $d$, contains the values to which all elements in each row of $\mathbf{A}$ tend to in the long run. Note that the long-run distribution is determined solely by the properties of the transition matrix $\mathrm{M}$ and is not affected by the initial state distribution vector $P_{0}$.

The calculated transitions are shown in columns (1) to (4) in Table 6. Column (5) includes 
the shares of regions for the different states in 1995, whereas Column (6) corresponds to the computed steady state share. For instance, the probability of a highly innovative region surrounded by highly innovative regions $(H H)$ to remain in its current state over one time period is 90.3 per cent (see row 1 and column 1), whereas the probability of remaining a $L L$ region accounts to 93.6 per cent on average (row 4 and column 4). All variables show fairly high off-diagonal probabilities. In particular, age dispersion shows relatively high transition probabilities reflecting high dynamics over time. The two transitions with the highest probabilities are generally those for regions moving from $L H$ to $H H$ and from $H L$ to $L L$, that is, transitions where a region absorbs the characteristics of its neighbours. In a recent paper, Hierro et al. (2013) interpret transitions from LH to HH as 'positive contagion', and those from HL to LL as 'negative contagion'. This result indicates that it is highly likely, for an outlier, to become part of its surrounding cluster. This is an interesting result, since it means, for example, that a region is negatively (positively) affected in its innovative performance by being surrounded by weakly (strongly) innovative regions.

Also, the probability of being absorbed by the neighbours' state is always higher than the one of the reverse outcome, and the gap in probability for the two events is greater for the negative outcome (i.e., it is more likely for an $H L$ region to become $L L$ than for an $L H$ region to become $H H$ ). The only exception are LH regions concerning the share of high-skilled, probably again because of the ongoing skill-selective out-migration. Our finding pertaining to the probability of joining the neighbours' state, albeit for different variables, seems to be in contrast with the one of Hierro et al. (2013), who stress that positive spatial contagion (transitioning from $L H$ to $H H$ ) is more likely to be expected than negative (from $H L$ to $L L$ ). Finally, movements from $L H$ to $L L$ and from $H L$ to $H H$ seem fairly high as well in the case of average age and age dispersion. Obviously, single regions may also end up pulling their neighbours up/down to their status, but the probability of this occurernce is much lower. Thus, the probability to reverse the trend, for underperforming regions with an old and homogenous age structure, for instance in East Germany, is low. There appears then to exist a clusterwise 'path dependence', where not only a region's own history influences its chances of modifying its status quo in the future (as it is normal to expect). Additionally, the surrounding environment plays a role in limiting the range of possible future outcomes, or in favouring different outcomes, when there is a mismatch between a region's state and the one of its surrounding areas. Clearly, such a hypothesis can only be formulated on the basis of our findings, but it will need to be thoroughly tested in 
further research by means of regression modelling.

We can now investigate the long-run results suggested by our data, by means of the ergodic steady-state distributions. We find that most regions were either LL or HH in 1995 and this appears to be true in the long run as well. For instance, 29.5 (49.4) per cent of regions were in a highly (lowly) innovative cluster in 1995 and the expected share in the long run is 28.3 (48.1) per cent (see columns (5) and (6) of Table 6). Also, except for innovation, all variables show that $L L$ clusters will become more important, with a decrease in the size/number of the HH clusters. Finally, the share of outliers is expected to increase (in particular HL), compared to the initial share in 1995. Our results (a shrinking and enlargement of $H H$ and $L L$ clusters respectively, and the emergence of more outliers) appear to signal an increase in the concentration of a variable in few specific regions. This seems to be the case, for example, for the share of high skilled. Finally, innovation seems much more stable in the long run, compared to the demographic measures.

Overall, the transition matrices presented above suggest that location matters for the evolution of regional innovation and workers' age structure and human capital. In particular, our results show that the evolution of a region depends on its neighbouring regions. The latter finding might explain why, for German regions, we currently observe clustering tendencies towards polarization. Transition probabilities also show that it is unlikely for a region to reverse the trend, suggesting strong neighbouring forces and clusterwise path dependence. In the long run, the production of knowldege is very unlikely to change. However, for demographic measures HH clusters will drop out while LL clusters will increase in extension.

Our findings may be reconsidered in an urban/agglomeration economics perspective. In particular, one might argue that it is necessary to investigate the determinants of the process we uncovered in this paper, and to verify whether this is consistent with what is suggested by the new economic geography (NEG) literature on agglomeration and to what extent.

\section{Conclusion}

This paper contributes to the debate on demographic change in Europe and its potential effects on innovative capability and regional disparities by exploring the spatio-temporal dynamics of regional innovation output, worker age structure and human capital for German regions. Besides commonly used tools, we apply newly developed approaches in order to detect spatial regimes or other forms of spatial heterogeneity for the investigated variables. To our knowledge, this 
paper is the first to provide such an in-depth explorative analysis, in terms of both spatial and temporal dynamics, on the topic.

Using global and local indicators of spatial correlation, we find specific clusters of highly innovative regions in urban and rural counties in West and South Germany. These hot spots mostly coincide with clusters of young and heterogenous workers. In contrast, less idea-driven regions cluster in rural and sparsely populated areas in East Germany and coincide with an old and homogenous working population. Interestingly, regions in East Germany with high skill shares are mostly part of an innovation hub, whereas this is not true for West Germany. We detect very few outliers, indicating that regions are unlikely to be a high (low) innovative region in a low (high) innovate spatial environment.

Applying newly developed visualization tools, we further investigate the space-time dynamics of the clusters. Our finding is that although few East German regions have slightly improved in terms of innovation, the overall spatial distribution has not changed much during the observed period. Our results for the age structure reveal a strong demographic polarization trend: major cities are experiencing declining average ages (relative to the national value), whereas the age distribution of rural areas is shifting upwards. East Germany with a large rural landscape is particularly negatively affected by these trends, thus the demographic divide between both parts of the country is further increasing. Despite these developments, East German regions appear to be transitioning from a highly age-homogeneous workforce towards a more heterogenous one with lower human capital. This development may reflect the joint result of age-selective outmigration and retirement of the older workforce cohorts. In turn, East and West Germany have become similar in their age diversity and skill composition.

Overall, our results reveal a great divide across German regions. The geography of innovation shows not one, but two 'Germanies': Innovation hubs with young and age heterogenous workers on the one hand side and less idea-driven regions with old and homogenous workers on the other. The specific dynamic patterns observed suggest that the divide will further increase along agglomeration lines. In particular, major cities are gaining importance for young and educated workers since agglomerated ('thick') labour markets increasingly offer several advantages such as cultural infrastructure and a better matching efficiency between workers and employers (see e.g. Moretti 2011, Buch et al. 2013). Our investigations show that losing regions thereby have a small probability to reverse the trend due to strong neighbouring forces and clusterwise path dependence. For policy makers of such regions it will therefore become more important to 
develop strategies to counteract the geographical poverty trap such as 'big push' type of policies to move the region to a good equilibrium (Moretti 2011, Kline 2010).

Our findings also have implications for future work in this field. In particular, our in-depth exploratory analysis may serve as a departure point for any analysis trying to measure the impact of demographic ageing on firm or regional performance. The presence of strong clustering in the demographic variables, and of very specific outliers with regard to innovation, suggests that spatial econometric techniques may be required when investigating such research question. From this point of view, it may be interesting to investigate whether demographic variables interact in pushing technological development. Additionally, the presence of clusters might be explicitly modelled in a regression framework to incorporate, for example, threshold effects in the development of innovation capability. Alternatively, one might be interested in linking our finding of a stronger concentration of highly performing regions to the theoretical and applied literature on agglomeration, and to test the consistency of this finding in other contexts. 


\section{References}

ACs, Z., L. Anselin, And A. VArga (2002): "Patents and innovation counts as measures of regional production of new knowledge," Research policy, 31(7), 1069-1085.

Anger, S., AND K. Lupo (2004): "Bildungsrenditen von Vollzeitbeschäftigten in Deutschland: der Osten hat aufgeholt," Wochenbericht, 74(10), 149-157.

Anselin, L. (1988): Spatial Econometrics: Methods and Models. Kluwer Academic, Dordrecht.

- (1995): "Local Indicators of Spatial Association-LISA," Geographical Analysis, 27(2), $93-115$.

- (1996): "The Moran scatterplot as an ESDA tool to assess local instability in spatial association," Spatial analytical perspectives on GIS, 4, 121.

(2001): Spatial Econometrics, B. Baltagi (ed.): Companion to Econometrics. Basil Blackwell, Oxford.

Anselin, L., And R. J. Florax (1995): "Small sample properties of tests for spatial dependence in regression models: Some further results," in New directions in spatial econometrics, pp. 21-74. Springer, Berlin, Heidelberg.

Arntz, M., T. Gregory, and F. Lehmer (2011): "Unequal pay or unequal employment? What drives the skill-composition of labor flows in Germany?," ZEW Discussion Papers 11074, Center for European Economic Research.

Brunow, S., And G. Hirte (2006): "Age structure and regional economic growth," Jahrbuch für Regionalwissenschaft, 26(1), 3-23.

Buch, T., S. Hamann, A. Niebuhr, and A. Rossen (2013): "What Makes Cities Attractive? The Determinants of Urban Labour Migration in Germany," Urban Studies, forthcoming.

Burda, M. C., And J. Hunt (2001): "From Reunification to Economic Integration: Productivity and the Labor Market in Eastern Germany," Brookings Papers on Economic Activity, $32(2), 1-92$.

Cressie, N. (1993): Statistics for spatial data. John Wiley \& Sons, London. 
DALL'ERBA, S. (2005): "Distribution of regional income and regional funds in Europe 19891999: an exploratory spatial data analysis," The Annals of Regional Science, 39(1), 121-148.

Ertur, C., AND W. Koch (2006): "Regional disparities in the European Union and the enlargement process: an exploratory spatial data analysis, 1995-2000," The Annals of Regional Science, 40(4), 723-765.

Fazio, G., And L. LAVECChia (2013): "Social capital formation across space: proximity and trust in European regions," International Regional Science Review, 36, 296-321.

Feyrer, J. D. (2008): “Aggregate Evidence on the Link Between Age Structure and Productivity," Population and Development Review, 34, 78-99.

Fitzenberger, B., A. Osikominu, and R. Völter (2006): "Imputation Rules to Improve the Education Variable in the IAB Employment Subsample," Schmollers Jahrbuch: Journal of Applied Social Science Studies, 126(3), 405-436.

Fratesi, U., And M. R. Riggi (2007): "Does Migration Reduce Regional Disparities? The Role of Skill-Selective Flows," Review of Urban and Regional Development Studies, 19(1), $78-102$.

GIESE, E. (2002): "The spatial pattern of invention activities in West Germany 1992-1994," in Technological change and regional development in Europe, pp. 9-27. Physica Verlag, Heidelberg, New York.

Giese, E., And von Reinhard Stoutz (1998): "Indikatorfunktion von Patentanmeldungen für regionalanalytische Zwecke in der Bundesrepublik Deutschland," Raumforschung und Raumordnung, 56(5-6), 414-420.

Glaeser, E. L. (1999): "Learning in Cities," Journal of Urban Economics, 46(2), 254-277.

GriLiches, Z. (1998): "Patent statistics as economic indicators: a survey," in RED and Productivity: The Econometric Evidence, pp. 287-343. University of Chicago Press.

Hierro, M., A. Maza, and J. Villaverde (2013): "A proposal for detecting spatial contagion: Some evidence on the international migration distribution in Spain," Papers in Regional Science, forthcoming. 
Hunt, J. (2004): "Are migrants more skilled than non-migrants? Repeat, return, and sameemployer migrants," Canadian Journal of Economics, 37(4), 830-849.

Jaffe, A. B., M. Trajtenberg, and R. Henderson (1993): "Geographic localization of knowledge spillovers as evidenced by patent citations," the Quarterly journal of Economics, 108(3), 577-598.

Kanbur, R., And H. RApoport (2005): "Migration selectivity and the evolution of spatial inequality," Journal of Economic Geography, 5(1), 43-57.

KLine, P. (2010): "Place based policies, heterogeneity, and agglomeration," The American Economic Review, 100(2), 383-387.

Laurent, T., A. Ruiz-Gazen, and C. Thomas-Agnan (2012): "GeoXp: An R Package for Exploratory Spatial Data Analysis," Journal of Statistical Software, 10(2), 1-23.

Le Gallo, J. (2004): "Space-time analysis of GDP disparities among European regions: A Markov chains approach," International Regional Science Review, 27(2), 138-163.

Le Gallo, J., and C. ERTur (2003): "Exploratory spatial data analysis of the distribution of regional per capita GDP in Europe, 1980-1995," Papers in regional science, 82(2), 175-201.

LeSAGE, J., ANd R. PACE (2009): Introduction to spatial econometrics. Chapman \& Hall/CRC, Boca Raton.

Lindh, T., And B. MAlmberg (1999): "Age structure effects and growth in the OECD, 19501990," Journal of population Economics, 12(3), 431-449.

Moretti, E. (2011): "Local Labor Markets," in Handbook of Labor Economics, ed. by D. Card, and O. Ashenfelter, vol. 4, Part B, chap. 14, pp. 1237 - 1313. Elsevier.

Patacchini, E., and P. Rice (2007): "Geography and economic performance: exploratory spatial data analysis for Great Britain," Regional Studies, 41(4), 489-508.

Patuelli, R., D. A. Griffith, M. Tiefelsdorf, and P. Nijkamp (2012): "Spatial Filtering Methods for Tracing Space-Time Developments in an Open Regional System: Experiments with German Unemployment Data," in Societies in Motion: Regional Development, Industrial Innovation and Spatial Mobility, pp. 247-68. Edward Elgar. 
Patuelli, R., N. Schanne, D. Griffith, and P. Nijkamp (2012): "Persistence of Regional Unemployment: Application of a Spatial Filtering Approach to Local Labor Markets in Germany," Journal of Regional Science, 52(2), 300-23.

PugA, D. (2002): "European regional policies in light of recent location theories," Journal of Economic Geography, 2(4), 373-406.

REY, S. (2001): "Spatial empirics for economic growth and convergence," Geographical Analysis, $33(3), 195-214$.

Rey, S. J., A. T. Murray, and L. Anselin (2011): "Visualizing regional income distribution dynamics," Letters in Spatial and Resource Sciences, 4(1), 81-90. 


\section{Appendix}

Table 7: Regional characteristics by agglomeration type, East and West Germany (1995-2008)

\begin{tabular}{lcccc}
\hline & $\begin{array}{c}\text { Patents } \\
\text { per 100 workers }\end{array}$ & $\begin{array}{c}\text { Average } \\
\text { age }\end{array}$ & $\begin{array}{c}\text { Age } \\
\text { dispersion }\end{array}$ & $\begin{array}{c}\text { Share of } \\
\text { high-skilled }\end{array}$ \\
\hline $\begin{array}{l}\text { West Germany (n=3738) } \\
\text { independent (major) cities }\end{array}$ & 3.66 & 40.43 & 10.30 & 8.39 \\
$\begin{array}{l}\text { urban counties } \\
\text { rural counties (with }\end{array}$ & 7.55 & 40.15 & 10.36 & 5.04 \\
$\quad$ concentration tendencies) & 5.58 & 39.79 & 10.50 & 3.39 \\
sparsely populated rural counties & 3.14 & 39.72 & 10.46 & 2.99 \\
\hline $\begin{array}{l}\text { East Germany (n=910) } \\
\text { independent (major) cities }\end{array}$ & 1.97 & 41.16 & 10.28 & 12.45 \\
$\quad \begin{array}{l}\text { urban counties } \\
\text { rural counties (with }\end{array}$ & 0.89 & 41.25 & 10.21 & 6.74 \\
$\quad$ concentration tendencies) & 1.20 & 41.18 & 10.17 & 6.47 \\
sparsely populated counties & 1.00 & 41.19 & 10.07 & 5.48 \\
\hline
\end{tabular}




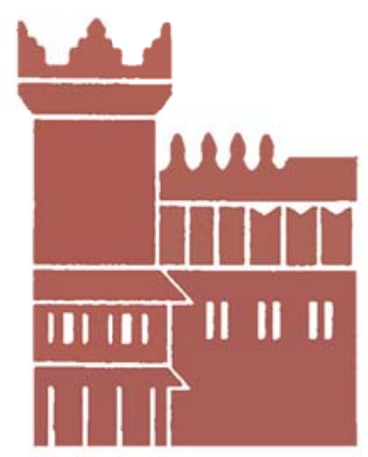

Alma Mater Studiorum - Università di Bologna DEPARTMENT OF ECONOMICS

Strada Maggiore 45

40125 Bologna - Italy

Tel. +39051 2092604

Fax +390512092664

http://www.dse.unibo.it 